\title{
Topiltzin actor
}

\section{Topiltzin Actor}

Artículo recibido el I2 de febrero de 20I9; aceptado el 20 de agosto de 20I9; https://doi.org/IO.2220I/ iie.18703062e.2020.117.2732

Arnold Lebeuf Jagiellonian University, Cracovia, Institut d'Histoire des Religions, a.lebeuf@iphils.uj.edu.pl

Líneas de investigación Historia y mitología de Mesoamérica; religión, ritual y teatro.

Lines of research History and myths of Mesoamerica; religion, ritual and theater.

Publicación más relevante Arnold Lebeuf, Les éclipses dans l'ancien Mexique (Cracovia: Jagiellonian University Press, 2003).

Resumen Este ensayo analiza las cuatro páginas de los Anales de Cuaubtitlan que tratan la vida y muerte de Quetzalcóatl. En él, me ciño a un punto de vista: revisar las fuentes históricas que refieren a Quetzalcóatl a la luz de lo que sabemos del teatro del misterio religioso en el México prehispánico, representaciones teatrales que culminan con el sacrificio del actor principal o bien de toda la agrupación. Algunos autores opinan que Quetzalcóatl fue un personaje histórico y otros que fue una figura únicamente mítica, aunque es posible que fuese ambos. Los Anales de Cuaubtitlan describen una o más representaciones históricas de un libreto mitológico.

Palabras clave Quetzalcóatl; sacrificio humano; teatro en el México antiguo.

Abstract This essay analyses the four pages the Annals of Cuaubtitlan that present the life and death of Quetzalcoatl. Bound by a single objective, I review sources concerning Quetzalcoatl taking into account what we know about religious mystery theatre in ancient Mexico, those theatrical representations culminating in the sacrifice of the leading actor and sometimes of the entire troupe. Some authors claim Quetzalcoatl was an historical figure, whereas others sustain he was purely mythological; although he probably was both. The Annals of Cuauhtitlan describe one or more historical representations of a mythological script.

Keywords Quetzalcoatl; human sacrifice; theatre in ancient Mexico. 
Résumé Cet essai analyse les quatre pages du texte des Annales de Cuaubtitlan qui traitent de la vie et de la mort de Quetzalcóatl. Je me suis limité à un seul point de vue : celui de relire les sources concernant Quetzalcóatl à la lumière de ce que nous savons du mystère religieux dans le Mexique préhispanique, représentations théâtrales se terminant par le sacrifice de l'acteur principal et parfois de tout son entourage. Quetzalcóatl fut-il un personnage historique comme le soutiennent les uns ou une figure mythique comme l'affirment les autres? Il est possible qu'il ait été tout à la fois entièrement mythologique et entièrement historique parce que le texte des Annales fait référence à une ou des représentations jouées historiquement d'un libretto mythologique.

Mots-clés Quetzalcóatl; sacrifice humain; théâtre dans l'ancien Mexique. 
https://doi.org/10.22201/iie.18703062e.2020.117.2732

\author{
ARNOLD LEBEUF \\ JAGELLONIAN UNIVERSITY, POLONIA
}

\title{
Topiltzin actor
}

Consideramos como culminación de la representación típica de un rito prehispánico el sacrificio de una victima humana, donde la ficción ritual se derrama dramáticamente en la realidad. Patrick Johansson ${ }^{1}$

L

e présent texte constitue une partie d'un manuscrit plus étendu sur les quatre pages du texte des Annales de Cuaubtitlan qui traitent de la vie de Quetzalcóatl. Les commentaires concernant ce personnage sont nombreux. Certains ont été écrits dès le XVI siècle par les chroniqueurs espagnols et d'autres par des indigènes élevés dans l'ancien système, ou leurs descendants directs, métis christianisés et éduqués à l'espagnole, souvent bien informés, conscients et fiers de leur passé. Tous, bien que pour des motifs différents, voulaient noter et sauver de l'oubli ce qu'il restait de l'ancienne culture d'avant la conquête. Depuis les premières mentions de Quetzalcóatl aux tout débuts de la conquête espagnole et jusqu'aujourd'hui, cet intérêt ne s'est jamais tari. Les études sur Quetzalcóatl sont très nombreuses, de sorte que reprendre le sujet pourrait paraître une entreprise vaine et inutile. Henri B. Nicholson ${ }^{2}$ et Michel Graulich ${ }^{3}$ nous en ont livré des historiographies très érudites et

I. Patrick Johansson, "La mort de Quetzalcóatl: un modèle exemplaire pour les obsèques des seigneurs mexicains», Caravelle. Cahiers du Monde Hispanique et Luso-Brésilien, nr.78 (2002): 5-36.

2. Henri B. Nicholson, Topiltzin Quetzalcóatl, the Once and Future Lord of the Toltecs (Boulder: University Press of Colorado, 200I).

3. Michel Graulich, Quetzalcóatl y el espejismo de Tollan (Anvers: Instituut voor Amerikanis- 
parfaitement documentées. Bien d'autres auteurs ont aussi rapporté, commenté et discuté d'abondance les sources et les hypothèses de leurs prédécesseurs à propos de Quetzalcóatl. Il ne s'agit donc pas ici d'essayer d'exploiter l'ensemble de la littérature pour la discuter, puisque cela a déjà été fait de manière très satisfaisante et selon divers éclairages et points de vue, mais de se concentrer sur les paragraphes 27-52 des Annales de Cuaubtitlan, ${ }^{4}$ quatre pages ${ }^{5}$ d'une écriture serrée traitant de Quetzalcóatl, le roi de Tollan, qui constituent en quelque sorte le noyau dur de tout ce qui peut se rapporter à ce personnage. Ce texte est d'une singulière sobriété. Il nous manquera à tout jamais la richesse expressive de sa déclamation ou de ses représentations, gestes, mimes, chorégraphies, accompagnements sonores de tambours, flûtes, grelots, cris, silences et les décors de fleurs et de plumes, les nuages de fumée de copal, la fascination silencieuse des auditeurs, les débordements émotifs des spectateurs, le giclement du sang. Mais d'autres textes, d'autres représentations, les commentaires naïfs ou savant peuvent nous aider un peu à nous imaginer ce qui habillait autrefois ce squelette:

Se entiende sin dificultad lo que perderá la síntesis expresiva vocal cuando vengan a desaparecer en la escritura alfabética el esplendor de los trajes, el oro y las plumas, significación simbólica inmanente al personaje que ninguna mediación verbal podría reproducir sin oscurecerla. ${ }^{6}$

Je me suis limité à un seul point de vue, celui de relire les sources concernant Quetzalcóatl à la lumière de ce que nous savons du mystère religieux dans le Mexique préhispanique, représentations théâtrales se terminant invariablement par le sacrifice de l'acteur principal et parfois de tout son entourage. Ici encore, les travaux sur le théâtre et sur le sacrifice de Ángel María Garibay; ${ }^{7}$ Yólotl

tik, 1988); Michel Graulich, «Los reyes de Tollan», Revista Española de Antropología Americana, nr. 32 (2002): 87-II4.

4. Selon la classification des Annales de Cuaubtitlan, in Códice Chimalpopoca, Anales de Cuauhtitlan y Leyenda de los Soles, Primo Feliciano Velásquez, ed. y trad. (Ciudad de México: Universidad Nacional Autónoma de México, 1975), IX-X.

5. Les 6 dernières lignes de la page 3 du manuscrit; les pages 4,5,6,7; et les 4 premières lignes de la page 8 .

6. Patrick Johansson, La palabra, la imagen y el manuscrito (Ciudad de México: Universidad Nacional Autónoma de México, 2004), 86.

7. Ángel María Garibay K., Historia de la literatura náhuatl (México: Porrúa 1953-1954). 
https://doi.org/10.22201/iie.18703062e.2020.117.2732

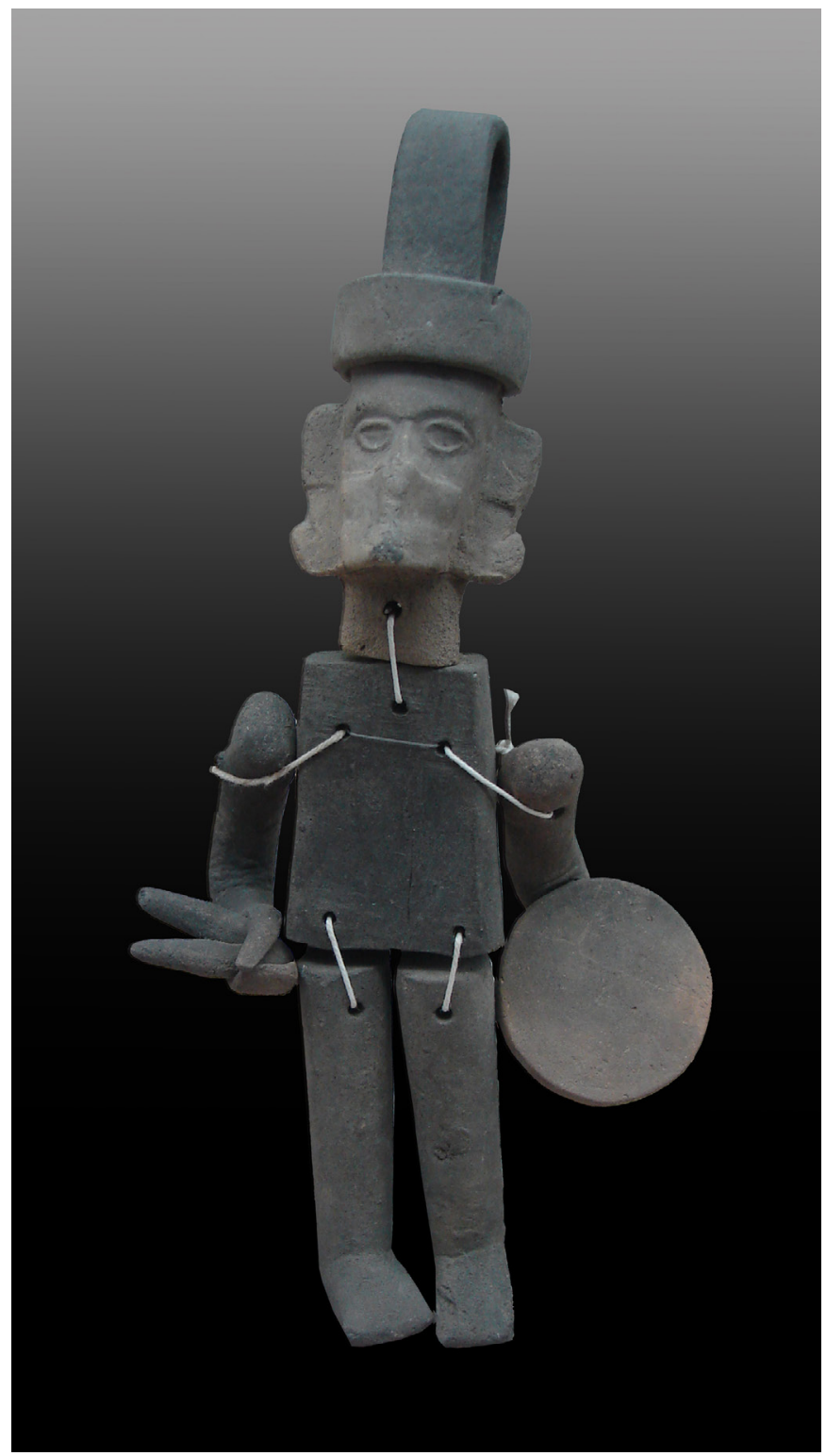

I) Ehecatl Quetzalcóatl, l'acteur Topiltzin, pantin de terre cuite. Museo de Tehuacán, Puebla. Secretaría de Cultura-INAH-MÉx. "Reproducción autorizada por el Instituto Nacional de Antropología e Historia”. 
Gonzáles; ${ }^{8}$ Michel Graulich; ${ }^{9}$ Miguel León Portilla; ${ }^{10}$ Alfredo López Austin; ${ }^{11}$ Patrick Johansson $;{ }^{12}$ Fernando Horcasitas, ${ }^{13}$ sont très utiles et facilitent grandement la tâche. Il n'y a guère de sources utiles que ces auteurs n'aient signalées et discutées en ce qui concerne les trois pieds de mon objectif:

I) Les traditions concernant Quetzalcóatl.

2) Le sacrifice humain dans le Mexique préhispanique.

3) Les représentations théâtrales du mystère divin dans l'ancien Mexique.

Comme tout ou presque a déjà été dit, mon apport propre se borne donc à réexaminer les sources d'un point de vue différent, à changer d'optique et d'éclairage. Quetzalcóatl fut-il un personnage historique comme le soutiennent les uns ou une figure mythique comme l'affirment les autres? Il est possible que ces luttes incessantes entre les tenants de la thèse historique et ceux de l'explication mythologique aient été inutiles, que les uns comme les autres aient eu raison et que le personnage en question, Quetzalcóatl, ait été tout à la fois entièrement mythologique et entièrement historique. Comment justifier une telle gageure? La solution serait la suivante. L'histoire de Quetzalcóatl, grand roi des Toltèques et grand dieu de nombreuses cultures de Mésoamérique durant des siècles est de pure mythologie, certes, mais comme en Mésoamérique la religion se présentait principalement comme rituel, comme représentation théâtrale de la vie et de la mort des dieux, cette mythologie avait été représentée publiquement de très nombreuses fois dans de nombreuses régions et durant de longs siècles. Ces rituels et représentations avaient donc été, eux, on ne peut plus historiques. Il me semble que le texte des Annales de

8. Yólotl González Torres, El sacrificio humano entre los mexicas (Ciudad de México: Fondo de Cultura Económica/Instituto Nacional de Antropología e Historia, 2006).

9. Graulich, Quetzalcóatl y el espejismo de Tollan; Michel Graulich, Montezuma ou l'apogée et la chute de l'empire aztèque (Paris: Fayard, 1994); Graulich, "Los reyes de Tollan»; Michel Graulich, Le Sacrifice humain chez les Aztèques (Paris: Fayard, 2005).

Io. Miguel León Portilla, "Teatro náhuatl prehispánico», La Palabra y el Hombre. Revista de la Universidad Veracruzana (1959).

II. Alfredo López Austin, Hombre-Dios. Religión y politica en el mundo náhuatl (Ciudad de México: Universidad Nacional Autónoma de México, 1998).

I2. Patrick Johansson, Teatro mexicano y dramaturgia (Ciudad de México: Consejo Nacional para la Cultura y las Artes, I992); Johansson, «La Mort de Quetzalcóatl»; Johansson, La palabra, la imagen y el manuscrito.

13. Fernando Horcasitas, El teatro náhuatl, épocas novohispana y moderna (Ciudad de México: Universidad Nacional Autónoma de México, 2004). 
Cuaubtitlan n'est ni mythologique ni historique mais les deux à la fois, parce qu'il fait référence à une ou des représentations jouées historiquement d'un mystère divin considéré comme éternel, anhistorique.

Les Annales de Cuaubtitlan sont une composition anonyme en langue nahuatl. Après une discussion serrée des origines possible de ce texte, Primo Feliciano Velázquez conclue qu'il est très probable qu'il ait été composé par Alonso Vexerano de Cuauhtitlan, Martin Jacobita de Tlaltelolco et Pedro de San Buenaventura de Cuauhtitlan entre 1558 et 1570 et aurait fait partie des rapports et manuscrits rédigés à la demande de Sahagún. ${ }^{14}$ Ceci est bien possible puisque de tous les textes concernant la saga de Quetzalcóatl, ceux du manuscrit nahuatl du Códice Matritenses ${ }^{15}$ sont les plus proches du texte des Annales de Cuauhtitlan. Le texte des Annales serait donc le document original qui servit à Sahagún à recomposer son «Histoire» de Quetzalcóatl, ce qui nous le rend d'autant plus précieux. Les auteurs présumés étaient selon Sahagún lui-même les plus savants de ses informateurs. Garibay pense que le texte des Annales est une compilation de fragments poétiques mutilés et mal conservés: «Una larga serie de fragmentos en que se canta la vida, hechos y ruina de Quetzalcóatl... mutilado y mal conservado, es con todo de la más valiosa aportación de este género». ${ }^{16}$ Mais que veut dire exactement Garibay par ce terme de «chanter»? A-t-il utilisé ici une forme littéraire du verbe conter, ou déclamer une épopée? faire des louanges? ou, parlant au sens strict, veut-il désigner une pièce chantée, accompagnée de musique et autres décors? le texte des Annales serait alors ce qu'il resterait d'une représentation bien plus fastueuse, plus proche des traditions de l'opéra que du récit historique, l'opéra des dieux.

14. Annales de Cuauhtitlan, IX-X.

15. Bernardino de Sahagún, Códice Matritense de la Real Academia de la Historia, textos en náhuatl de los indígenas informantes de Sahagún, edición facsimilar de Paso y Troncoso (Madrid: Hauser y Menet, 1907); Bernardino de Sahagún, "Códice Matritense», en Primeros memoriales, Wigberto Jiménez Moreno, trad., pról. y comentarios (Ciudad de México: Instituto Nacional de Antropología e Historia, 1974); Bernardino de Sahagún, «Códice Matritense», Primeros memoriales. Paleography of Náhuatl Text and English Translation, Thelma Sullivan, ed., Completed and Revised, with Additions, by Henry B. Nicholson, Arthur J.O. Anderson, Charles E. Dibble, Eloise Quiñones Keber and Wayne Ruwet (Norman: University of Oklahoma Press,1997); Sahagún, Códice Matritense del Real Palacio, fols. I6Iv y ss., I32V-I34v. versión de A. M. Garibay, in Miguel León-Portilla, ed., Anónimo. Cantos y crónicas del México antiguo (Madrid: Dastin, 2002), 58-60; 76-77.

16. Garibay, Historia de la literatura náhuatl, I, 284. 
Nicholson écrit:

This important Nahuatl document is an unusually rich compilation of a large number of local histories of various important centres in the Basin of México and the Basin of Puebla. Unfortunately, the anonymous compiler(s) tried to force all these independent traditions into a continuous chronological framework, thereby producing a highly artificial and distorted account. ${ }^{17}$

Plus loin il ajoute, en se rapprochant de Garibay:

It almost certainly hails from some major centre in the Basin of México. Its exact date can also only be guessed at. It bears every indication however, of being derived from a genuine pre-Conquest narration, quite possibly in metered verse, and must have been recorded before the last elders educated in the calmecac had begun their journey to the Nine Fold Stream. ${ }^{18}$

Malgré toutes mes réticences à accepter la thèse abusivement historique de Nicholson, ce commentaire ne pouvait que me plaire, que dit-il? -Qu'en fait, les Annales de Cuaubtitlan pourraient bien être ce qu'il reste d'un texte versifié, et pour le Méxique préhispanique ceci implique nécessairement une pièce jouée et mimée avec musique et dance, décors et mise en scène, et que son origine est authentiquement préhispanique. Et d'ailleurs, le même Nicholson qui défend contre vents et marées la thèse historique note très lumineusement dans ses conclusions que l'analyse de toutes les sources présente: «A kind of tragic "drama in seven acts," then, can be tentatively reconstructed as the most fundamental version of the tale as known from the core group of Central Mexican sources».19 Les Annales de Cuaubtitlan sont donc une compilation d'œuvres plus anciennes, sans doute abrégées, ce qui est bien regrettable, parce que les sources dans lesquelles a puisé le rédacteur de ce manuscrit sont d'une exceptionnelle richesse et chaque mot y compte. Je ne serais pas bien d'accord avec le jugement sévère de Garibay selon lequel le texte serait mutilé et mal conservé. Qu'il ait été écourté, soit, mais ce qu’il en reste me semble exceptionnellement bien conservé, et bien que de toute évidence il s'agisse d'un

17. Nicholson, Topiltzin Quetzalcóatl, the Once and Future Lord, 39.

18. Nicholson, Topiltzin Quetzalcóatl, the Once and Future Lord, 39.

19. Nicholson, Topiltzin Quetzalcóatl, the Once and Future Lord, 252. 
collage de fragments provenant de sources diverses, comme le voit aussi Graulich: «El autor desconocido de los Annales de Cuauhtitlan compone su obra basándose en fuentes diferentes, de lo que resultan confusiones», ${ }^{20}$ ces fragments ont été assemblés de manière à en faire une nouvelle œuvre d'art dont la composition ne laisse pas à désirer, à la manière de ces masques funéraires en mosaïques de jade dont les morceaux peuvent provenir de pièces récupérées sur d'autres compositions détruites mais ont été parfaitement réassemblés pour en faire une nouvelle ouvre structuralement parfaite. Leurs auteurs premiers faisaient certainement partie de ces indigènes de classe supérieure eux-mêmes directement éduqués dans les traditions précolombiennes qu'ils rapportent. A ce qu'il me semble, dans les Annales de Cuaubtitlan en général et dans cette partie en particulier, l'influence européenne est négligeable et ne dépasse pas l'usage de qualificatifs tels que celui de démon ${ }^{21}$ pour désigner Tezcatlipóca ou de formules conventionnelles telles que le On dit que dans son idolâtrie. ${ }^{22} \mathrm{~A}$ part ces quelques rajouts diplomatiques, le texte est d'une parfaite authenticité. Les mythes ont la vie dure et résistent aux pires destructions parce qu'ils ont, comme les hydres, la faculté de se reconstituer à partir d'un quelconque fragment: «La vie d'un peuple renferme des éléments intimes qui non seulement triomphent du choc le plus violent, mais se maintiennent à travers les âges et arrivent presque dans toute leur intégrité jusqu’à la postérité la plus éloignée». ${ }^{23}$ Il serait bien étonnant que ce texte ne soit pas original puisque les autres textes que nous possédons, bien que provenant de divers auteurs indépendants et de diverses cultures et époques, se complètent et se confirment les uns les autres en dépit des variantes et des apparentes contradictions. Nous ne pouvons sérieusement croire que les auteurs du Xvi siècle aient tous recopié une seule et même source ou se soient tous plagiés les uns les autres, et d'ailleurs, si c'était le cas, les ressemblances seraient bien plus serrées, les différentes versions seraient quasi identiques, ce qui n'est pas le cas.

20. Graulich, Quetzalcóatl y el espejismo de Tollan, 91.

21. Annales, 38; Johansson, La mort de Quetzalcóatl, I8, traduit littéralement «Hommes-hiboux» du nahuatl «tlatlacatecolo», qui se traduit généralement par sorcier, démon, mais peut aussi désigner un prêtre.

22. Annales de Cuauhtitlan, 36 .

23. Remi Siméon, Introduction à Chimalpahin, sixième et septième relation (Paris: Maisonneuve et Leclerc, eds., I889), introd. VI. 
Voyons Mendieta:

Otros dijeron que Tezcatlipoca (de quien arriba se hizo mención, que era el ídolo principal de México) había descendido del cielo descolgándose por una soga que había hecho de tela de araña, y que andando por este mundo desterró á Quetzalcóatll, que en Tulla fué muchos años señor, porque jugando con él a la pelota, se volvió en tigre, de que la gente que estaba mirando se espantó en tanta manera, que dieron todos a huir, y con el tropel que llevaban y ciegos del espanto concebido, cayeron y se despeñaron por la barranca del río que por allí pasa, y se ahogaron; y que el Tezcatlipóca fué persiguiendo al dicho Quetzalcóatll de pueblo en pueblo, hasta que vino a Cholula, donde le tenían por principal ídolo, y allí se guareció y estuvo ciertos años. Mas al fin el Tezcatlipuca, como más poderoso, le echó también de allí, y fueron con él algunos de sus devotos hasta cerca de la mar, donde dicen Tlillapa ó Tizapan, y que allí murió y le quemaron el cuerpo; y que de entonces les quedó la costumbre de quemar los cuerpos de los señores difuntos. Y que el alma del dicho Quetzalcóatl se volvió en estrella, y que era aquella que algunas veces se ve echar de sí un rayo como lanza: y algunas veces se ha visto en esta tierra la tal cometa o estrella, y tras ella se han visto seguir pestilencias en los indios, y otras calamidades [...]. Pues volviendo al Quetzalcóatl, algunos dijeron que era hijo del ídolo Camaxtli, que tuvo por mujer á Chimalma, y de ella cinco hijos, y de esto contaban una historia muy larga. Otros decían, que andando barriendo la dicha Chimalma, halló un chalchihuitl (que es una pedrezuela verde) y que la tragó, y de esto se empreńó, y que así parió al dicho Quetzalcóatll. ${ }^{24}$

Il est clair qu'il s'agit d'une autre source très différente de celle des Annales de Cuauhtitlan, mais nous y trouvons pourtant plusieurs points communs et des convergences. Nous remarquerons aussi que chez Mendieta ce texte concernant Quetzalcóatl est inclus dans le paragraphe dédié á Tezcatlipoca! Parfois ennemis et parfois frères et collaborateurs dans la même œuvre de création.

24. Gerónimo de Mendieta, Historia eclesiástica indiana, 4 vols. (Ciudad de México: Salvador Chávez Hayhoe, 1945), 88-89, in Graulich, Quetzalcóatl y el espejismo de Tollan, I82. 


\section{Les origines chrétiennes de Quetzalcóatl}

Bien que je trouve des idées intéressantes dans l'article d'Emanuela Mónaco, ${ }^{25}$ je ne puis être d'accord avec son interprétation structurale brossant un portrait de Quetzalcóatl taillé sur mesure pour plaire aux chrétiens espagnols. Les catégories et les questions mises en œuvre dans ce texte sont trop universelles et trop profondes pour ne pas être authentiques. Bien que je ne crois pas du tout dans ce cas à un problème de diffusion historique, l'auteur qui remarque si justement que: No casualmente Quetzalpetlatl significa «trono y poder del quetzal» (es suficiente recordar que Isis significa "trono»), ${ }^{26}$ aurait pu éviter de prendre à la légère la sainteté de l'invitation à l'ivresse que Quetzalcóatl présente à sa sœur. L'auteur abonde dans l'interprétation du péché, de la chute morale de Quetzalcóatl:

La acción llevada a cabo por Quetzalcóatl en estado de ebriedad - la de llamar a su hermana - seguramente responde a una interpretación del episodio en términos morales. Él, vencido por los demonios tentadores, arrastra en su corrupción a una mujer, y, por ańadidura, a una mujer que, siendo su hermana, con mayor razón la habría tenido que proteger y preservar del mal y de la corrupción. La acción aparece mucho más indigna ya que Quetzalpetlatl se dedica a una vida de santidad. ${ }^{27}$

Le fait est plutôt que lorsque l'on vient chercher Quetzalpetlatl pour l'offrir à Quetzalcóatl, le roi, le grand prêtre, elle n'oppose aucune résistance, au contraire, elle répond, à la bonne heure: «Sea en hora buena. Vamos, abuelo y paje", selon le texte, et "Voy inmediatamente»... selon l'auteur. ${ }^{28}$ Quelque chose ne va pas dans cette interprétation de la chute morale. Et puis, les éléments qui composent ce texte sont trop bien confirmés par d'autres aspects des cultures préhispaniques de Mésoamérique, par l'iconographie et l'archéologie et trouvent trop de parallèles frappants et significatifs chez d'autres peuples du grand ensemble des cultures indigènes de l'Amérique pour avoir été empruntés à l'Europe chrétienne. Il suffit d'ailleurs de lire les quelques pages que Diego Durán consacre à Topiltzin Quetzalcóatl pour voir qu’en toute honnêteté,

25. Emanuela Mónaco, «Quetzalcóatl de Tollan», Arqueología I9, segunda época (I998): II9-I55.

26. Mónaco, «Quetzalcóatl de Tollan», 137.

27. Mónaco, "Quetzalcóatl de Tollan», I36-I37.

28. Mónaco, «Quetzalcóatl de Tollan», I36. 
il ne doutait pas un instant de l'originalité des légendes, des signes et des gestes rapportés par les indigènes de la Nouvelle Espagne. Bien au contraire, certaines déclarations des indigènes ou l'observation de certains rites et coutumes le laissèrent stupéfait, essayant de comprendre les inquiétantes similarités que ces traditions présentaient avec l'enseignement des évangiles. Durán croit y trouver l'effet déformé, abâtardit d'une évangélisation précoce des Indes par saint Thomas:

Las azañas y maravillas de Topiltzin y de sus hechos heroicos son tan celebrados entre los indios y tan mentados y casi con apariencias de milagros, que no sé qué me atreva a afirmar ni escribir de ellos, sino que en todo me sujeto a la corrección de la santa iglesia católica. Porque aunque me quiera atar al sagrado evangelio que dice por San Marcos que mandó Dios a sus sagrados apóstoles que fuesen por el mundo y predicasen el evangelio a toda criatura, prometiendo a los que creyesen y fuesen bautizados la vida eterna, no me osaré afirmar en que este varón fuese algún apóstol bendito. Pero gran fuerza me hace su vida y obras a pensar que, pues estas eran creaturas de Dios racionales y capaces de la bienabenturanza, que no las dejaría sin predicador, y si le hubo fue Topiltzin. El cual aportó a esta tierra, y según la relación del se da, era cantero que entallaba imágenes en piedra y las labraba curiosamente. Lo cual leemos del glorioso Santo Tomás. ${ }^{29}$

Les ressemblances avec le christianisme sont trop frappantes pour ne pas inquiéter un homme aussi instruit que Fray Diego Durán, chroniqueur, théologien et prêtre catholique qui revient plusieurs fois sur son étonnement:

Es de notar que la figura presente se solemnizaba en nombre de 'Padre' que quiere decir tota, para que sepamos que reverenciaban al padre y al hijo y al espíritu santo, y decían tota, topiltzin y yolometl, los cuales vocables quieren decir 'nuestro padre, y nuestro hijo y el corazon de ambos', haciendo fiesta a cada uno en particular y a todos tres en uno, donde se nota la noticia que hubo de la trinidad entre esta gente..$^{30}$

A veinte de marzo, un día después que agora la iglesia sagrada celebra la fiesta del glorioso San Josef, celebraban en esta tierra los indios una solemnísima

29. Diego Durán, Historia de las Indias de Nueva España e Islas de la Tierra Firme, A. M. Garibay, ed., 2 vols. (México: Porrúa, 1984), 9-10.

30. Durán, Historia de las Indias de Nueva España, I: VIII: 86. 
fiesta y tan regocijada y ensangrentada y tan a costa de hombres, que no había otra más que ella. Llamábanla Tlacaxipeualiztli que quiere decir «desollamento de hombres», y era la primera fiesta del ańo de las del número de su calendario, que ellos celebraban de veinte en veinte días. En la cual, demás de ser de las fiestas de este número, celebraban en ella a vn ídolo que, con ser vno, lo adoraban debajo de tres nombres, y, con tener tres nombres, lo adoraban por uno, casi a la mesma manera que nosotros creemos en la Santísima Trinidad, que es tres personas distintas y un solo Dios verdadero: así esta gente creía en este ídolo ser vno por debajo de tres nombres, los quales eran Totec, Xipe, Tlatlauhqui Tezcatl. La declaración de los cuales nombres será necesario poner, para que entendamos lo que quieren significar, y cómo todas las cerimonias y solemnidad se enderezaban a honor de estos tres nombres y de cada uno en particular. El primer nombre que es Totec, aunque al principio no le hallaba denominación y me hizo titubear, en fin, preguntando y tornando a preguntar, vine a sacar que quiere decir «seńor espantosso y terrible», que pone temor. El segundo, que es Xipe, quiere decir «hombre desollado y maltratado»; el tercer nombre, que es Tlatlauhqui Tezcatl, quiere decir «espejo de resplandor encendido». Y no era ídolo particular que lo celebraban aquí y allí pero era fiesta universal de toda la tierra, y todos lo solenizaban como a dios universal, y así le tenían un templo particular con toda la honra y suntuosidad posible..$^{3 t}$

Durán revient donc plusieurs fois à cette inquiétante ressemblance des croyances indigènes avec la Sainte Trinité, qui l'étonne tant. Lire ici le mot «étonner» au sens fort, selon son étymologie: frappé du tonnerre, de la foudre, stupéfait, saisi de stupeur. Je ne crois pas ici non plus que Durán ait interprété les traditions mexicaines à la mode chrétienne. Il se serait sans doute plus volontiers passé de telles singularités historiques et humaines, et de ce mélange incompréhensible d'éléments apparemment si chrétiens avec des pratiques idolâtriques et des mœurs scandaleux pour un européen de l'époque. C'est surtout ce mélange inextricable qui devait sembler totalement blasphématoire et diabolique, et beaucoup plus qu'une pure idolâtrie exotique, et c'est bien pour cela que Durán est inquiet. Mais Durán, grâce à Dieu, est d'une honnêteté toute à son honneur. Il veut s'assurer d'avoir bien compris, et retourne demander des précisions chez ses informateurs: "al principio no le hallaba denominación y me hizo titubear, en fin, preguntando y tornando a preguntar, vine a sacar».32

3I. Durán, Historia de las Indias de Nueva España, I: IX: I-3: 95.

32. Durán, Historia de las Indias de Nueva España, I: IX: 2:95. 
Ce fragment sent si fort la vérité! La formulation me fit tituber trahit bien son émotion lorsqu'il croit reconnaître une forme exotique de la Sainte Trinité chrétienne dans la tradition locale, ce qui démontre complètement qu'il ne saurait s'agir d'un syncrétisme, il était trop tôt pour cela. Et d'ailleurs cette unité des trois personnes divines entre parfaitement dans les possibilités logiques de la pensée religieuse mésoaméricaine avec tout son système de traductions, déplacements et substitutions des ixiptla, ${ }^{33}$ des images. Durán est si stupéfait de ce qu'il croit comprendre, que ne pouvant le croire, il retourne pour s'informer. Durán se compte ici parmi les plus anciens et les plus scrupuleux des ethnographes. Il lui faut retourner s'informer pour s'assurer qu'il a bien compris, qu'il n'a pas interprété ce qu'on lui a dit. La passion de la vérité à tout prix, comme le meilleur des enquêteurs du roman policier. Durán remarque ces ressemblances frappantes des évangiles non seulement avec les traditions orales des indiens, mais encore avec certains aspects de leur rituel, et surtout du plus fondamental, lorsque celui-ci présente une idole du dieu en pâte d'amarante que les fidèles se partagent en communion:

quise contar el modo que esta gente tenía de sacrificar, y quice hacer capítulo particular de ello, por lo mucho que hay de notar, así en el sacrificio, como en los particulares ministros que para ello había. Donde, después de acabada la cerimonia y bendición de aquellos trozos de masa en figura de hueso y carne del ídolo, en cuyo nombre eran reverenciados, y honrados con la veneración y acatamiento con que nosotros reverenciamos al divino sacramento del altar. ${ }^{34}$ [Et encore,] La cual carne de todos los sacrificados tenían realmente por consagrada y bendita, y la comían con tanta reverencia y con tanta cerimonias y melindres, como si fuera alguna cosa celestial. ${ }^{35}$

Il semble pourtant garder quelques réserves quant à une possible évangélisation précoce des Indes occidentales par Saint Thomas, mais il est vraiment convaincu

33. Image, double, représentant, etc.

34. Durán, Historia de las Indias de Nueva España, I: III: I-2:31. Avec de tels documents à disposition, on s'étonne un peu qu'en 1975 Schwarz puisse se demander si l'idée de transcendance se rencontre au Mexique et déclarer «so far as we know they do not appear in the Mayan-Aztec civilisations» dans un essai pour le numéro spécial de Daedalus sur le thème de la transcendance, in Gordon Willey, préface à H.B. Nicholson, Topiltzin Quetzalcóatl, the Once and Future Lord, XVI.

35. Durán, Historia de las Indias de Nueva España, I: X: I4:Io8. 
que les indiens sont les descendants des tribus perdues d'Israël. Le premier chapitre de son Historia est un long plaidoyer de cette explication, une hypothèse qui refait surface tout au long de son œuvre, comme par exemple pour commenter le nom de Malinalco lieu de sédentarisation de la tribu de Malinalxochitl, Durán s'écrit: «Y esta es costumbre de esta generación: poner el nombre al pueblo de su primer fundador. Costumbre judaica». ${ }^{36}$ Durán espère trouver la Bible et l'Evangile, mais ailleurs il s'interroge, il balance entre deux possibilités, celle d'une précoce évangélisation et celle d'une farce cruelle de Satan:

Acabadas las cerimonias, bailes y sacrificios, entremeses y juegos que entre los dioses había - digo entre aquellos que los representaban - íbanse a desnudar, y los sacerdotes y dignidades del templo tomaban el ídolo de masa y desnudábanle aquellos aderezos que tenía, y así a él como a los trozos que estaban consagrados en huesos y carne suya, hacíanlos muchos pedacitos y, empezando desde los mayores, los comulgaban con ellos a todo el pueblo, chicos y grandes, hombres y mujeres, viejos y niños, y recibíanlo con tanta reverencia y temor y lágrimas que era cosa de admiración, diciendo que comían la carne y huesos del dios; teniéndose por indignos de ello. Los que tenían enfermos pedían para ellos y se lo llevaban con mucha reverencia y veneración. Todos los que comulgaban quedaban obligados a dar diezmo de aquella semilla de que se hacía aquella masa para la carne y huesos del dios. Note el lector qué propiamente está contrahecha esta cerimonia endemoniada la de nuestra iglesia sagrada que nos manda recibir el verdadero cuerpo y sangre de nuestro señor Jesucristo, verdadero Dios y verdadero hombre por Pascua florida... De lo cual se colijen dos cosas: o que hubo noticia - como dejo dicho - de nuestra sagrada religión en esta tierra, o que el maldito de nuestro adversario el demonio las hacía contrahacer en su servicio y culto, haciéndose adorar y servir, contrahaciendo las católicas cerimonias de la cristiana religión. ${ }^{37}$

On remarquera avec beaucoup d'intérêt sa formulation: «los dioses... digo entre aquellos que los representaban». Durán n'est pas le seul à chercher dans les croyances et pratiques religieuses mexicaines le signe d'une évangélisation précoce de l'Amérique, par exemple Ixtlilxochitl décrit Quetzalcóatl comme précurseur ou prémonition du christianisme. «llegó a esta tierra un hombre a quien llamaron Quetzalcóatl y por otro nombre Huemac, virgen, justo y santo, el que

36. Durán, Historia de las Indias de Nueva España, II: III: 24:32.

37. Durán, Historia de las Indias de Nueva España, I: III: 22-24:35. 
vino de la parte del oriente y enseño la ley natural y constituyó el ayuno evitando todos los vicios y pecados; el primero que colocó y estableció la cruz».38

Il cherche evidemment à se conforter dans sa nouvelle foi, n'ayant déjà plus le choix, mais en même temps sauver l'ancienne en la rendant acceptable dans la nouvelle culture en création, il veut complaire aux espagnols mais aussi se vanter que ses ancêtres connaissaient eux aussi une religion sublime et morale, ce qui ne veut pas dire que ce qu'il déclare soit de pure invention.

Bien loin du Mexique central, au pays Maya, Las Casas s'interroge aussi au sujet d'une possible première évangélisation:

un hombre muy hermoso había por allí pasado e les había dejado aquella señal para que del siempre se acordasen. Otros diz que afirmaban que porque habían muerto en ella un hombre más resplandeciente que el sol: esto refiere Pedro Mártir en el capítulo ${ }^{\circ}$ de su cuarta Década. ${ }^{39}$

Et qui donc aurait propagé ces croyances et d'autres plus chrétiennes encore? Un certain Kukulcan (le nom maya de Quetzalcóatl), qui était arrivé au Yucatan avec I9 compagnons: «Si estas cosas son verdad, parece haber sido en aquella tierra nuestra santa fe notificada.$^{40}$

Torquemada signale que Quetzalcóatl portait la croix: «Dicen de este Dios Quetzalcóatl, que viviendo en esta vida mortal, vestía de vestiduras largas hasta los pies, por honestidad, con una manta encima, sembrada de cruces coloradas». ${ }^{4 \mathrm{I}}$

Comment n'auraient-ils pas été surpris de trouver en Amérique un fils de dieu, né d'une mère fécondée par le ciel, doux ermite innocent, victime de la méchanceté du pouvoir et mourant pour la rédemption de son peuple tant

38. Fernando de Alva Ixtlilxóchitl, Obras históricas, Edmundo O’Gorman, ed. (Ciudad de México: Instituto Mexiquense de Cultura, 1997), I:529-530.

39. Bartolomé de las Casas, Obras completas, vol. (Madrid: Alianza Editorial [1988-1994], 1992), 882.

40. Las Casas, Obras completas, 883 .

4I. Juan de Torquemada, Monarquía indiana, 3 t. (Ciudad de México: Editorial Porrúa, 1986, [edición facsímile de la edición de Madrid de 1723]), VI: XXIV; II: 52: I; Andrés de Tapia rapporte la même information (Relación hecha por el senor Andres de Tapia, sobre la conquista de México, in Colección de documentos para la historia de México, Joaquín García Icazbalceta, ed., vol. 2 (Ciudad de México: J. M. Andrade, I866), 554-594, 573. Les exemples iconographiques et archéologiques de Quetzalcóatl portant une croix ou marqué d'une croix sont nombreux, voir entre autres Vaticanus 3738 planche $7 \mathrm{v}$. 
aimé? Le fait même que les premiers chroniqueurs du XvI siècle aient cherché désespérément une telle explication historique à la présence de similitudes si frappantes avec le christianisme démontre parfaitement que ces traditions sont bien originales, sinon ils auraient tous tempêté contre les déformations intolérables que les indiens opéraient sur les enseignements des prêtres récemment venus leur porter la vraie foi, ils se seraient lamentés sur les insurmontables difficultés de l'évangélisation de ces peuples sauvages. Mais non, ce qu'ils trouvent c'est une tradition locale, authentiquement préhispanique qui ressemble trop dangereusement à l'évangile pour ne pas poser de graves problèmes historiques, philosophiques et théologiques. Et d'ailleurs, d'autres prêtres de la même époque voulaient résoudre ces inquiétantes similitudes d'une manière radicalement opposée, en les présentant comme farces cruelles et moqueries de Satan. En effet, certains auteurs du XVI ${ }^{\text {e }}$ siècle, épouvantés par les sacrifices, et autres diableries, et peu enclins à se comparer à une telle humanité, ni capables d'accepter ce mélange de spiritualité quasi chrétienne, de barbarie charnelle et de cruautés insupportables, un mélange baroque qui n'était pas encore de mode dans la vieille Europe, n'y ont voulu voir qu'une singerie moqueuse et cruelle du Démon, de Satan, du Grand Menteur. Par exemple le Père De Los Rios pour lequel les légendes qui rapportent que Quetzalcóatl est né de Chimalman après qu'un ambassadeur de la voie lactée (Citlallatonac) lui ait annoncé la naissance d'un fils, ne sont que malice du démon:

Aquí fingen los miserables ciertos sueńos de su ceguedad, diciendo que un dios que se decía Citlallantónac, que es aquel signo que se ve en el cielo llamado camino de Santo Santiago o Vía Láctea, mandó un embajador del cielo con una embajada a una virgen que estaba en Tulan, que se llamaba Chimalman,... a la cual dijo el embajador que aquel dios quería que concibiese un hijo, y que oyendo la embajada se levantó y barrió la casa y tan luego como la barrió concibió un hijo, sin contacto con hombre, el cual fue llamado Quetzalcóatlle... No dejaré de notar en este lugar la astucia de nuestro adversario que desde hace tanto tiempo inventó esta falsedad entre esta pobre gente a fin de que, si en cualquier tiempo tuvieran noticia del principio del misterio de nuestra redención, que fue cuando el ángel Gabriel fue mandado por Dios a la virgen María... lo atribuyesen al padre de la mentira falsificada y contrecha en este falso dios Citlallantónac, y en su embajador, y en esta virgen. ${ }^{42}$

42. Codex Vaticanus 3738, vol. III, lám. VIII, 26, en Lord Kingsborough, Antigüedades de México (London: 1964). 
Le bon prêtre dénonce les illusions mensongères de l'ennemi des bons chrétiens, des hommes et de Dieu, il méprise les croyances indigènes mais en très bon père leur octroi d'avance le pardon pour leurs erreurs, les plaint sincèrement d'avoir été fourvoyés de manière si dégoutante, tout rempli d'une compassion condescendante.

Joseph de Acosta pour sa part se permet de comparer les onguents diaboliques des prêtres mexicains avec le Saint Chrême, ${ }^{43}$ et au chapitre 24, il ne peut que s'émerveiller de la duplicité et astuce du diable pour imiter la vrai religion et s'attirer la dévotion due à Jésus: Capitulo XXIV De la manera con que el demonio procuró remedar la fiesta de Corpus Christi, y comunión que usa la santa Iglesia... Suit une longue description de la fête de Huizilopochtli et du partage de sa figure en graines d'amarante et miel pour essayer d'imiter la vraie et sainte communion. Tous ne sont pas aussi admiratifs devant les astucieuses tromperies du démon. Mendieta s'étonne innocemment et sans rire que le malin ait été si peu malin dans ses imitations de la vraie foi:

Para haber de orar a sus dioses, no sabían qué cosa era ponerse de rodillas, sino en cuclillas, como suelen estar para parlar o descansar, en que se ve la poca reverencia en que tenían a sus dioses; y es de maravillar cómo el demonio, pues apetece ser adorado y reverenciado en la forma y manera que ese mismo dios, no les enseñó el ponerse de rodillas cuando le hacían oración. ${ }^{44}$

C'est charmant.

Sahagún trouve, lui aussi, diabolique l'insupportable simulacre de l'eau bénite:

Otro diablo adoraron vuestros antepasados, al qual llamaron nappatecutli: dixeron que era el dios de los que hazen petates y icpales... El sacerdote deste dios, que ellos llamavan ixiptla, que quiere dezir su ymagen: acostumbrava andar por las casas, con una xicara con agua en la una mano, y un ramo de salze en la otra,

43. Joseph de Acosta, Historia natural y moral de las Indias. De la unción abominable que usaban los sacerdotes mexicanos y otras naciones, y de sus hechiceros (Ciudad de México/Buenos Aires: Fondo de Cultura Económica, 1962), 262-263.

44. Gerónimo de Mendieta, Historia eclesiástica indiana, Cien de México (Ciudad de México: Secretaría de Educación Pública, 1997), 93. 
y rociava con el ramo las casas y personas bien como quien echa agua bendita, y todos lo recibian con gran devocion. ${ }^{45}$

Dans toutes ces réflexions nous ne trouvons pas la moindre trace de syncrétisme religieux. Oui, les croyances et les rites des indigènes de l'Amérique ressemblent scandaleusement à ceux des chrétiens, et les seules manières de s'en sortir honorablement et de ne pas blasphémer est de chercher les traces d'une évangélisation précoce malheureusement défigurée par la distance et la perte de contact avec la Sainte Mère l'Eglise de Rome ou sinon une astuce révoltante du Malin. Nous n'en sommes pas encore aux études de religions comparées. On en remarque les éléments mais sans pouvoir en déduire encore les conclusions nécessaires et inévitables, parce que trop intolérables, inacceptables, blasphématoires. En dépit de leurs conclusions si opposées, aucun de ces auteurs ne met en doute l'origine locale et ancienne, préhispanique des traditions qu'ils rapportent et les stupéfait pour leurs incompréhensibles similarités avec certains éléments fondamentaux du christianisme.

\section{Les commentaires des auteurs anciens}

Plusieurs lettrés et curieux des siècles suivants se posèrent les mêmes questions que les premiers chroniqueurs et arrivèrent aux mêmes conclusions. Mais comme plus tard, les érudits n'oseront plus faire appel à Saint Thomas, aussi voudront-ils faire croire à un emprunt dès les premiers temps de la conquête, un syncrétisme religieux et culturel, ce qui procède de la même logique. Pourtant, lorsque l'on trouve de telles ressemblances dans les éléments culturels de diverses nation, il n'est pas nécessaire d'en conclure une diffusion des valeurs et coutumes du vainqueur, ce qui serait d'une ridicule vanité. Lorsque Tezozómoc décrit la détresse des épouses des guerriers partis en campagne et leur angoisse de ne plus jamais les revoir, et se couvrent la tête de cendres en signe

45. Bernardino de Sahagún, Códice Florentino. Manuscrito 2I8-20 de la Colección Palatina de la Biblioteca Medicea Laurenziana, 3 vols. (Ciudad de México: Secretaría de Gobernación/ Archivo General de la Nación, 1979 [edición facsimilar]), I: Apéndice: 39v-40r; Bernardino de Sahagún, Historia General de las Cosas de Nueva Espana, 3 vols., versión íntegra del texto castellano del manuscrito conocido como Códice Florentino, Alfredo López Austin y Josefina García Quintana, estudio introductorio, paleografia, glosario y notas, Cien de México (Ciudad de México: Secretaría de Educación Pública/Consejo Nacional para la Cultura y las Artes, 2000), I24. 
de deuil et de pénitence, il écrit: «Y las mugeres de estos soldados mexicanos, en señal de jamas los beer boluer, començaron luego a ayunar, poner çeniza en sus cabeças, señal de gran tristeza, y jamas se lauauan». ${ }^{46}$ Est-ce par désir de plaire aux espagnols en citant la Bible: «Despojándose de sus magníficos vestidos, se vistió de angustia y duelo. En vez de exquisitos perfumes, echó sobre su cabeza ceniza y suciedad». ${ }^{47}$ Et: «Mardochée, ayant appris tout ce qui se passait, déchira ses vêtements, se revêtit d'un sac et se couvrit la tête de cendre». ${ }^{8}$ Et lorsqu'il rapporte que sous Moctezuma les adultères étaient lapidés ${ }^{49}$ est-ce encore parce que l'Amérique fut peuplée par une des tribus perdues d'Israël? Et l'auteur du Popol Vuh avait-il lu Saint Jean lorsqu'il décrit le commencement du monde: "Entonces vino la Palabra ${ }^{\circ \circ}$ qui ressemble tant à notre $A u$ début était le verbe, incipit de l'évangile de Saint Jean? ${ }^{\text {sI }}$ Certainement pas, et la volute de parole fleurie qui sort du copilli, en haut de la Piedra del Sol signifie sans doute l'acte de création de la divinité suprême. ${ }^{22}$

Brinton l'avait bien vu:

Furthermore, if the myths of the American nations are shown to be capable of a consistent interpretation by the principles of comparative mythology, let it be recognized that they are neither to be discarded because they resemble some familiar to their European conquerors, nor does that similarity mean that they are historically derived, the one from the other. Each is an independent growth, but as each is the reflex in a common psychical nature of the same phenomena, the same forms of expression were adopted to convey them..$^{3}$

Pour ma part, je crois que s'il y eut quelques contaminations des traditions européennes et chrétiennes dans le corpus de données qui nous a été légué sur Quetzalcóatl, celles-ci sont de peu d'importance. Premièrement parce que l'évangélisation au XVI siècle fut très superficielle et que les indiens ne prirent

46. Alvarado Tezozómoc, Crónica mexicana (Madrid: Dastin, 200I), XXX, I39.

47. Bible de Jérusalem, traduite en français sous la direction de l'école biblique de Jérusalem (Paris: éditions du Cerf, 1998), Esther, XIV: 2.

48. Bible, Esther, IV: I.

49. Tezozómoc, Crónica mexicana, CV; 453; Bible, Deut. 22: 23-24.

50. Popol Vuh, Adrián Recinos, ed. y trad. (México: Fondo de Cultura Económica, 1953), 86.

5I. Bible, Evangile, Jean, I: I.

52. Arnold Lebeuf, "El Sol 4-Ollin de los aztecas», Arqueología, nr. 39 (2008): Io8-I4I.

53. Daniel Brinton, American Hero Myth (Philadelphia: H.C. Watts \& Co.,1882), 35-36. 
des enseignements des prêtres que ce qui leur convenait, ce qui pouvait s'intégrer sans grand mal à leur cosmovision, aux structures fondamentales et profondes de leur culture propre. Il semble que les éléments adaptables parce que fondamentalement semblables aient été nombreux. Et puis, ne serait-ce pas à nouveau le signe d'une grande cécité culturelle, d'une superbe et grande suffisance que de croire toujours que les autres se sont calqués sur nous et sur notre religion dominante, le christianisme. Les ressemblances sont nombreuses, certes, entre le christianisme et ce que l'on sait des religions de Mésoamérique, mais les ressemblances seraient bien plus grandes encore si l'on voulait comparer les religions de l'ancien Mexique avec par exemple l'hindouisme. Cela a-til conduit à parler d'un syncrétisme hindou-mexicain? Ce serait donc plutôt le christianisme qui aurait largement puisé au fond commun religieux protohistorique ou préhistorique de l'humanité. Que l'on ne s'étonne donc pas de découvrir quelques ressemblances! Les explications en faveur d'un emprunt ou d'un syncrétisme sont ridicules. Lorsque nous rencontrons de frappantes ressemblances avec le christianisme, n'allons donc pas croire qu'il ne s'agit que d'une forme mineure empruntée, une singerie grotesque. Les ressemblances sont plus profondes, structurales. Et d'ailleurs, Michel Graulich avait déjà largement argumenté dans ce sens en reconnaissant l'origine authentiquement préhispanique de thèmes comme ceux de l'arbre brisé du paradis perdu, de la maternité virginale, du déluge, de l'exode, etcetera. ${ }^{54}$ Et il avait très justement proposé une explication plus plausible, dans la lignée de Brinton:

la antigua religión del Altiplano mexicano tal como se la presenta aquí es en cierta medida una religión de salvación más que una religión de tipo arcaico, analítico, no totalizante, dependiente del pensamiento mítico. Desde el siglo xvi, a los misioneros les sorprendieron algunos rasgos que evocaban sus propias creencias, pero no se dieron cuenta o no quisieron darse cuenta de que la misma economía del sistema era muy equiparable a la del cristianismo. 5

Depuis le début des études deux courants principaux se sont affrontés. Les uns voulant montrer la teneur historique des traditions du roi des Toltèque

54. Michel Graulich, «Myths of Paradise Lost in Pre-Hispanic Central Mexico», in Current Anthropology, vol. 24, no. 5 (1983): 575-588; Michel Graulich, «L'arbre interdit du paradis aztèque», Revue de l'Histoire des Religions 207, I (1990): 3I-64.

55. Graulich, Quetzalcóatl y el espejismo de Tollan, 43. 
et identifier archéologiquement la capitale de son royaume, Tollan, les autres rejetant l'hypothèse historique pour mettre l'accent sur les aspects purement mythiques du personnage. ${ }^{56}$ Ces deux points de vue apparaissent depuis le tout début puisque les chrétiens qui ont vu dans les traditions américaines concernant Quetzalcóatl la marque d'une évangélisation précoce s'attachaient à une vision diffusionniste, et donc historique, alors que ceux qui dénoncèrent une manipulation diabolique penchaient pour l'explication mythologique, une affabulation, une illusion. Chez les chrétiens, Dieu est historique et le démon n'est qu'un menteur, un illusionniste. Lui-même un mensonge, une illusion peut être? Bien sûr, les tenants de l'hypothèse historique admettent qu'il se soit mêlé un peu ou plus qu'un peu de légende dans les chroniques, et les partisans du mythe ne peuvent nier certains aspects apparemment historiques et chronologiques, mais la contradiction résiste. Dans son étude magistrale Hombre-Dios, Alfredo López Austin rajoute une troisième école dans laquelle il se situe lui-même et qu'il fait remonter à López de Gomara, l'humaniste: «no vacilaría en colocar a López de Gomara entre los autores del tercer enfoque, con los historiadores que se esfuerzan por separar los elementos míticos de los históricos». ${ }^{57} \mathrm{Si}$ je trouve très utile, et même indispensable d'un point de vue scientifique, de faire la part des choses, de s'efforcer de séparer la réalité historique de l'affabulation religieuse et littéraire, il faut aussi prendre en compte que telle distinction n'est pas vraiment pertinente pour le sujet qui nous occupe. Nous devons considérer que pour les civilisations du Mexique préhispanique tous ces aspects étaient intimement enlacés et confondus dans ce qui pour eux était la réalité historique. Et nous devons, nous aussi, accepter cette réalité préhispanique comme telle si nous voulons garder l'espoir de comprendre le message qui nous a été transmis. L'ensemble des mythes, légendes, croyances et rituels qui nous ont été légués forment un tout que nous devons prendre tel quel, comme il se présente, c'est-à-dire comme réalité historique de cette civilisation que nous cherchons à mieux comprendre. Patrick Johansson a parfaitement raison de dire qu'en Mésoamérique, tout n'est que convention et que l'apparence - c'est - la réalité.

56. Graulich, Quetzalcóatl y el espejismo de Tollan; López Austin, Hombre-Dios. Religión y politica en el mundo náhuatl; Nicholson, Topiltzin Quetzalcóatl, the Once and Future Lord, ont fait la revue de ces différentes approches.

57. López Austin, Hombre-Dios. Religión y politica en el mundo nábuatl, I5. 
En el México antiguo, todas representaciones poéticas se presentaban disfrazadas: Si el señor mandaba a los maestros y cantores que cantasen y bailasen el cantar que se llama Cuechtecayotl, tomaban los atavíos del areito conforme al cantar y se componían con cabelleras y máscaras pintadas, con narices agujeradas y cabellos bermejos, y traían la cabeza ancha y larga como lo usan los Cuechtecas y traían las mantas tejidas a manera de red..$^{88}$

Toute la réalité est jouée, c'est à dire dominée par sa sublimation artistique, son artifice. Le monde n'est appréhensible que sous sa forme représentée, et toute la gamme des incarnations artificielles de la réalité est mise à profit: «Un relato indígena de inspiración precolombina, contenido potencialmente en la memoria de los tlamatinime, se expresaba oralmente mediante una enunciación espectacular, en la que se entretejían gestos, sonidos, colores, ritmos, compases dancísticos, jeroglíficos indumentarios y otros elementos suprasegmentales que constituían, con el registro verbal, el texto manifiesto de dicho relatom.99

Si le mystère de l'identité de Topiltzin Quetzalcóatl s'est assez bien dissipé avec des travaux tels que ceux de Laurette Séjourné, ${ }^{60}$ de Jill Leslie Fürst, ${ }^{61}$ Henry B. Nicholson ${ }^{62}$ et surtout d'Alfredo López Austin ${ }^{63}$ et Michel Graulich ${ }^{64}$ de nombreuses questions restent ouvertes. En vérité, il est bien difficile de distinguer entre plusieurs figures majeures de Quetzalcóatl:

- Une divinité représentée sous la forme d'un serpent à plumes associé à la planète Vénus, que Nicholson groupe autour d'Ehecatl Quetzalcóatl.

- Un personnage historique réel dont on signale les parents et les grandsparents, son origine régionale, l'enfance à Amatlan, bourgade proche de Tepoztlan, ${ }^{65}$ Morelos, ou élevé par ses grand parents à Michatlauco près de Xochicalco pour Enrique Florescano, ${ }^{66}$ pour ne citer que deux de

58. Johansson, La palabra, la imagen y el manuscrito, 84 .

59. Johansson, La palabra, la imagen y el manuscrito, 23.

6o. Laurette Séjourné, El Universo de Quetzalcóatl (México: Fondo de Cultura Económica, 2003).

6I. Jill Leslie Furst, «The Year I Reed, Day I Alligator: A Mixtec Metaphor», Journal of Latin American Lore 4, nr. I (1978): 93-I28.

62. Nicholson, Topiltzin Quetzalcóatl, the Once and Future Lord of the Aztecs.

63. López Austin, Hombre-Dios. Religión y politica en el mundo náhuatl.

64. Graulich, Quetzalcóatl y el espejismo de Tollan.

65. Wigberto Jiménez Moreno, Historia de México (México: Porrúa, 1967), Ioo.

66. Enrique Florescano, «Tula-Teotihuacan, Quetzalcóatl y la toltecayotl», Historia Mexicana 13, nr. 2 (Oct.-Dec., 1963): 213. 
ces légendes historiques improbables; différentes traditions que Nicholson regroupe sous le nom de Topiltzin Quetzalcóatl. -Un personnage historique divinisé, le roi mythique des Toltèques, Topiltzin Quetzalcóatl de Tollan, dont presque toutes les dynasties de Méso-Amérique postclassique se voulaient héritières, personnage étudié par Alfonso Caso, ${ }^{67} \mathrm{Jill}$ Leslie Furst et Henry Nicholson.

- De nombreux prêtres ayant porté le titre de Quetzalcóatl Totec Tlamacazqui et Tlaloc Quetzalcóatl Tlamacazqui: ${ }^{68}$

- De nombreux avatars connus sous d'autres noms ou représentations graphiques dans d'autres cultures, tels que, Cinteotl, Cuculcan, Guacamatz, Nacxitl, etcetera.

- Quelques personnages qui semblent se confondre avec lui, comme Huemac, ${ }^{69}{ }^{6}$ Quetzalteueyac $^{70}$ ou les seigneurs 8-Mazatl et 4-Ocelotl des codex de la Mixteca. ${ }^{71}$

- Des truchements, images et personnifications rituelles du dieu, des Ixiptla.

Ignacio Bernal a proposé de résoudre la complexité et les difficultés présentées par l'extraordinaire variation du personnage en avançant qu'il s'agissait de différents prêtres ayant adopté ou reçu le titre de Quetzalcóatl, solution retenue aussi par Piña Chan:

Ignacio Bernal atiende a la complejidad de la historia del famoso Ce Acatl, rey de Tollan, que según él se debe a la costumbre de dar el nombre de Quetzalcóatl a todos los sacerdotes del dios, cuyas vidas se han fusionado en las crónicas. Esta idea, que ya se ha visto mencionada anteriormente, adquiría nueva importancia en unos cuantos ańos más, emitida por Pińa Chan. ${ }^{72}$

67. Alfonso Caso, Reyes y reinos de la mixteca. Diccionario biográfico de los señores mixtecos (México: Fondo de Cultura Económica, 1979).

68. Sahagún, Códice Florentino, III: Apendiz IX: 39 v; Sahagún, Historia General, 340.

69. Durán, Historia de las Indias de Nueva España, II: I: 30-3I:I4.

70. Paul Kirchhoff, Historia Tolteca Chichimeca (México: Instituto Nacional de Antropología e Historia /Secretaría de Educación Pública, 1976), fol. I6r.

7I. Maarten Jansen, «Los señoríos de Nuu Dzaui y la expansión tolteca», Revista Española de Antropologia Americana 36, nr. 2 (2006): 175-208, 191-192.

72. López Austin, Hombre-Dios. Religión y politica en el mundo nábuatl, 40. 
C'est une hypothèse satisfaisante à mon goût, mais encore insuffisante. Que signifie à vrai dire la dénomination de prêtre? -La victime quelle qu'elle soit pouvait être appelée courtoisement: Grand Prêtre, ou bien elle le devenait vraiment lorsqu'elle était désignée comme image du dieu pour être sacrifiée, comme on le lit bien dans les Annales: «Hijo mío, sacerdote Ce Acatl Quetzalcóatl, yo soy tu vasallo». En fait, tous sont les images et reflets, les Ixiptlas, les uns des autres, et pour cette raison elle-même peut-on donc facilement se perdre entre tous ces personnages. Par exemple, le premier chapitre du livre, Libro de los ritos y ceremonias en las fiestas de los dioses y celebración de ellas, de Durán commence justement par le chapitre sur Topiltzin: «De quien se sospecha que fue un gran varón que hubo en esta tierra, llamado Topiltzin, y por otro nombre Papa, a quien los Mexicanos llamaron Hueymac. Residió en Tula».73 Mais Quetzalcóatl n'occupe que le Vlème chapitre: «Del ídolo llamado Quetzalcóatl, dios de los Cholultecas, dellos muy reverenciado y temido, fue padre de los Toltecas, y de los españoles, porque anunció su venida».74 Il nomme le premier Gran Baron, et le deuxième idole comme s'il ne se rendait pas compte qu'il s'agit des facettes différentes du même personnage. Laurette Séjourné le comprend bien et reprend ces textes de Durán pour affirmer qu’il s'agit du même sous différents titres:

De lo que se deprende que estas dos colectividades se agrupan alrededor del mismo personaje, cuya trayectoria se inscribe en la sucesión de los nombres siguientes: Ehecatl (viento), Topiltzin (nuestro muy querido hijo), Quetzalcóatl (Serpiente Emplumada), Xolotl (doble), y también en las denominaciones sacadas de la posición del planeta Venus. ${ }^{75}$

Elle a tout à la fois raison et tort, comme nous le verrons plus bas.

Ce-Acatl - Ehecatl - Topiltzin - Quetzalcóatl - Tlahuizcal-pantecuhtli Xolotl - Venus est-il donc l'ancêtre des lignées royales et des communautés mentionnées ici et d'autres, une simple idole ou une planète? S'agit-il d'une chronique historique ou d'un récit mythique? Avec une telle diversité d'aspects attestés par les sources, l'abondance et la variété des commentaires qui lui ont

73. Durán, Historia de las Indias de Nueva España, I: I: 9.

74. Durán, Historia de las Indias de Nueva España, I: VI: 6I.

75. Laurette Séjourné, Cosmogonía de Mesoamérica (Ciudad de México: Siglo XXI, 2004), 260. 
été consacrés, il semble que tout déjà ait été dit de ce dieu - prêtre - roi de Tollan, et Thompson, il y a bien longtemps déjà s'était gaussé d'une telle situation en écrivant sur un ton plutôt acide: «Modern investigators have interpreted the quetzal-feathered serpent as a deity of almost everything under and including the sun».76

\section{Un personnage historique?}

Alfonso Caso propose de savantes reconstructions des généalogies royales issues de Quetzalcóatl dans la Mixteca. ${ }^{77}$ Sans ignorer le moins du monde les aspects religieux et transcendants du personnage, Nicholson penche décidément du côté de l'explication historique. Pour cela, il sépare assez strictement deux ensembles rattachés respectivement à Ehecatl Quetzalcóatl, la divinité, et Topiltzin Quetzalcóatl l'homme. Ceci constitue un parti pris classificatoire très utile sans doute, et permet d'éviter bon nombre d'abus d'interprétations, mais cette classification elle-même est abusive, artificielle et pour tout dire impossible. Nicholson en est parfaitement conscient:

This study aims only to examine one limited aspect of this larger problem, that relating to a large corpus of documentary source material that provides a number of different versions of what can be called the Topiltzin Quetzalcóatl of Tollan Tale, or at the least, significant allusions to its protagonist. The purely supernatural figure, whom I shall refer to as Ehecatl Quetzalcóatl, will receive only tangential consideration. With the cult and mythology of this old creator/wind/rain deity, symbolized by the feathered serpent, who clearly goes back well into the Classic period if not before, the personality and tale of Topiltzin Quetzalcóatl of Tollan seems to have become almost inextricably entwined. Separating the two is difficult, but a reasonably clear division can in most cases be made. Ideally, both aspects should be considered jointly, but this would demand a far more extensive investigation. It is the figure of historical legend, then, the man, not the god, who is the subject of this study $7^{78}$

76. Nicholson, Topiltzin Quetzalcóatl, the Once and Future Lord, XXVI, citant Thompson, 1945: 13.

77. Alfonso Caso, Reyes y reinos de la mixteca. Diccionario biográfico de los señores mixtecos. 78. Nicholson, Topiltzin Quetzalcóatl, the Once and Future Lord, XXVI. 
A la fin de son analyse, Nicholson affirme à nouveau l'historicité du personnage:

Topiltzin Quetzalcóatl, in spite of his concomitant quasi-divinity, was essentially a man who lived at a stated time and who moved through a world specifically located in space ${ }^{79}$ et encore: First and most important, I believe that it is quite possible that there was an "original» Topiltzin Quetzalcóatl, an actual person who lived on this earth but who later apparently became inextricably fused (and confused) with more than one deity - and probably with later rulers as well. ${ }^{80}$

On remarquera surtout dans ces fragments l'insistance sur le singulier, Topiltzin Quetzalcóatl est un personnage historique singulier, une personne définie dans le temps et l'espace. Nicholson ne veut pas voir que les différents aspects de Topiltzin Quetzalcóatl ne sont que les multiple facettes d'un ensemble inséparable et qu'il n'est ni possible ni nécessaire ni efficace de les séparer ou de chercher l'origine ou la version originale du personnage, la facette originale de toutes les autres puisque toutes font partie intégrante du personnage que nous cherchons à mieux définir et comprendre: "This well illustrates the fusion, or perhaps better, confusion, that had taken place between these two fundamentally distinct figures, the great ruler/priest of the Toltecs and the old fertility/creator god whose name he bore». ${ }^{81}$ Il revient sur cette distinction entre le dieu Ehecatl Quetzalcóatl et le roi Topiltzin Quetzalcóatl dans son introduction à l'édition de 200 m malgré toute l'évidence d'une impossibilité de séparer ces deux fonctions:

I probably should have mentioned, [...] the ascription of the creation of the Chichimeca ancestors of the major peoples of Central México, as well as the heavens, sun, and the earth, to «Topiltzin Quetzalcóatl»(Sahagún 1997: 223). As I noted in footnote 9 of this page, this particular binomial designation was usually reserved for the traditional Toltec ruler rather than the creator/wind deity, Ehecatl Quetzalcóatl, who was clearly intended here-but I also recognized that «at least by the time of the Conquest... their personas had intertwined to the extent that it is difficult to sharply differentiate them. ${ }^{82}$

79. Nicholson, Topiltzin Quetzalcóatl, the Once and Future Lord, 257.

80. Nicholson, Topiltzin Quetzalcóatl, the Once and Future Lord, 259.

81. Nicholson, Topiltzin Quetzalcóatl, the Once and Future Lord, 36.

82. Nicholson, Topiltzin Quetzalcóatl, the Once and Future Lord, XXXIII. 
Son choix constitue à mon sens une grave distorsion de la réalité. Non, les deux personnages ne sont pas deux figures distinctes. Pour être le plus connu, Nicholson n'est certes pas le seul à défendre la thèse historique. Le livre d'Alfredo López Austin, Hombre-dios est une œuvre capitale. Elle ne traite pas particulièrement du personnage de Quetzalcóatl, mais le prend comme l'une des figures exemplaires de ceux qu'il nomme les hommes-dieux. La plupart de ses réflexions sont d'une remarquable perspicacité, et il signale par moments quelques traits, quelques aspects qui auraient dû l'amener logiquement à une solution du problème proche de celle que nous proposons ici. Par exemple, à propos de l'ivresse de Quetzalcóatl, il écrit: «No es transgresión de un sacerdote original, sino la conducta de un dios en el mito, repetida ritualmente sobre la tierra». ${ }^{8} \mathrm{Il}$ semble toutefois qu'il n'ait pas voulu franchir le seuil du danger du blasphème, de la désacralisation de ce héro mythique si magnifique rédempteur du Mexique ancien. Il voit bien que parfois les héros, hommes-dieux sont en fait des victimes sacrificielles, mais chez lui cette catégorie reste marginale entre toutes les formes d'hommes-dieux qu'il présente. Il croit aussi que certains prêtres prenaient le rôle de victime représentant le dieu: «Una de las más duras funciones, naturalmente, era la occisión ritual. Hay vagas noticias de que algunos sacerdotes tomaban el papel del dios y morían representándolo». ${ }^{84}$ Il y eut sans doutes des cas de folie sacrée chez des fidèles possédés d'une rage mystique connue dans d'autres religions, le culte de Cybèle, par exemple, et prêts à se mutiler ou se tuer. Mais Alfredo López Austin ne considère pas les cas sans doute infiniment plus fréquents dans lesquels la victime n'avait rien choisi du tout, et n'était déclaré prêtre que le temps d'une représentation et bien malgré elle, ce qui n'empêchait nullement de s'adresser à elle par les termes de prêtre ou Grand-Prêtre, titres honorifiques que reçoit aussi Quetzalcóatl comme le veut le protocole religieux: «Tezcatlipoca; entró, le saludo y dijo: "Hijo mío, sacerdote Ce Acatl Quetzalcóatl"». ${ }^{85}$ López Austin fait donc de Quetzalcóatl un cas très exemplaire, mais somme toute un simple cas particulier d'un vaste ensemble de personnages qui présentent les mêmes particularités ou certaines d'entre elles. Nous sommes bien d'accord qu'il y eut une quantité de Quetzalcóatls, c'est à dire d'acteur du rôle, mais ce n'est

83. López Austin, Hombre-Dios. Religión y politica en el mundo náhuatl, 155.

84. López Austin, Hombre-Dios. Religión y politica en el mundo nábuatl, I8I, citant Francisco Hernández, Antigüedades de la Nueva España, trad. y notas de Joaquín García Pimentel (Ciudad de México: Editorial Pedro Robredo, 1946): 176-177.

85. Annales de Cuaubtitlán, 39. 
pas dans ce sens que López Austin parle de la multiplicité des Quetzalcóatl, il rassemble sous la catégorie générale des hommes-dieux des personnages à vrai dire très différents: héros nationaux et tribaux, prêtres, sorciers, shamans, ixiptla, nahuals, devins, rois, victimes, etcetera. Il voit bien que certains d'entre eux auraient pu être des prisonniers ou des esclaves manipulés, drogués, dépersonnalisés pour en faire les ixiptla des dieux, de simples acteurs, mais présente ces cas comme de simples exemples mineurs, presque marginaux de sa catégorie générale des hommes-dieux. Il ne voit pas ou ne veut pas voir que ce sont pour la plupart ces acteurs forcés du mystère divin qui sont justement à la base de toutes les autres imaginations pseudo historiques très idéalisées. Il voit bien que les ixiptla des dieux, se transformaient en nahual du dieu qui entrait en eux pour les posséder, qui prenait possession de leur enveloppe terrestre, mais présente cela comme une qualité particulière, exceptionnelle et stupéfiante, admirable, de certains êtres dotés de pouvoirs ou dons spéciaux, et ne veut pas voir que n'importe qui ou presque pouvait être attrapé, manipulé, opéré, lobotomisé, reprogrammé psychologiquement pour en faire un automate, un zombie, une simple enveloppe vide dans laquelle on pouvait insuffler l'esprit du dieu à représenter, reformater et reprogrammer totalement son comportement après un sérieux lavage de cerveau. Bref, en faire un acteur parfait. López Austin semble vraiment croire qu'il existait un type préhispanique de surhommes, et que ces personnages étaient véritablement dotés de pouvoirs surhumains et surnaturels, capables de prouesses mentales et spirituelles hors du commun, qu'ils avaient bien mérité de leurs réputations de dieux ou demi dieux, de héros culturels, chefs et maîtres spirituels de leurs communautés. Et pour lui, Quetzalcóatl fut donc un personnage (ou des personnages) historique doué de qualités exceptionnelles, surhumaines, en quelque sorte un saint homme. Son commentaire du passage suivant montre bien qu'il exclue de sa catégorie d'hommes-dieux les victimes, prisonniers ou esclaves achetés qui n'en pouvaient mais, et se seraient bien passé d'un tel honneur:

Cuando Motecuhzoma Xocoyotzin, alarmado por las seńales celestes de la desgracia, interpeló a la imagen viva de Huitzilopochtli, contestó el muchacho: ...que él era un pobre mozo ignorante y que de cosas del cielo él no alcanzaba nada, porque ni era astrólogo, ni hechicero, ni adivino. Que mandase llamar a los astrólogos y adivinos y a los que sabían de las cosas nocturnas y que le preguntase, que aquel era su oficio. ${ }^{86}$

86. López Austin, Hombre-Dios. Religión y politica en el mundo náhuatl, I83-184, citant Durán, Historia de las Indias de Nueva España, II: LXIII: 6:468. 
Et López Austin de commenter: «iA qué nivel habían llegado los salvadores de pueblos!» Ce qui montre bien qu'il croit vraiment aux qualités et pouvoirs exceptionnels des hommes-dieux, et n'a pas compris que pour la majorité ce sont de pauvres victimes innocentes, prises au piège d'une mécanique sociale infernale. Or dans la réponse de ce pauvre garçon, c'est de tout le contraire qu'il retourne, ce n'est pas $A$ quel niveau était tombée la fonction de «sauveur du peuple»! Cette réponse du jeune homme dont on avait voulu faire le pantin de dieu devrait bien plutôt soulever notre admiration, quelle grandeur dans cette réponse! Car contrairement à la grande majorité des autres victimes qui s’avouaient vaincues, résignées à la mort, et jouaient docilement les jeux des prêtres et de toute la société, celuici fait enfin preuve d'une saine et noble insolence et d'un esprit critique remarquable, d'une liberté absolue. Il peut bien se le permettre, se sachant condamné à mort de toutes manières. A vrai dire il insulte Moctezuma et avec lui ses prêtres et toute l'idéologie de l'empire. Les grands prêtres du pouvoir central de Tenochtitlan l'ont eux-mêmes désigné pour être le dieu suprême des aztèques, et en particulier le dieu absolument principal pour Moctezuma et tout le pouvoir Aztèque! Huitzilopochtli. Comment pourrait-on lui porter la contradiction? Par cette réponse il se moque de l'Empereur et déchire le voile de l'imposture religieuse, de l'idéologie du pouvoir. Moctezuma était d'une extrême dévotion, comment aurait-il pu châtier le dieu vivant? ce faisant il aurait complètement sapé les fondements idéologiques de l'empire. Le jeune homme, ixiptla de Huitzilopochtli prend Moctezuma à son propre piège. Peut-on s'imaginer qu'un simple jeune homme puisse se permettre une telle réponse à Moctezuma que même les plus grands nobles ne pouvaient regarder en face et qui envoyait à la mort tous ses contradicteurs. Mais qu'auraitil pu faire au dieu vivant? Parmi la masse des élus résignés et abattus, se trouvaient donc aussi quelques rares révoltés, superbes combattants de la liberté et de la vérité. Ces cas sont très rares, mais nous trouvons chez les Mayas une autre victime, cette fois féminine qui sauve sa vie par une insolence du même esprit, retournant contre les prêtres leur propre idolâtrie, superstition et crédulité:

Un anciano de Chichen Itzá relata un incidente, que asienta López Medel, según el cual a una joven a quien se iba a sacrificar se le exhortó a que pidiera después de su tránsito buenos temporales para sus cosechas; sin embargo, ella se rebeló y replicó que si la mataban pedirá el contrario. La joven fue sustituida por otra víctima. ${ }^{87}$

87. Martha Ilia Nájera Coronado, El don de la sangre en el equilibrio cósmico. El sacrificio y el autosacrificio entre los antiguos mayas (Ciudad de México: Universidad Nacional Autónoma 
Mais ces cas héroïques étaient rares sans doute. Les victimes sont trop souvent présentées comme des héros, des surhommes qui s'offraient avec résignation, indifférence, joie ou arrogance au couteau du sacrifice. Mon hypothèse nous amènera bien loin d'une telle idéalisation.

La liste des tenants de la thèse historique sont nombreux et l'on peut se demander comment les discussions sur l'historicité de Quetzalcóatl ont pu durer jusqu'aux temps présents puisque la chose avait été réglée dès la fin du XIX siècle. Brinton écrivait alors:

Why should we try to make a king of Itzamna, an enlightened ruler of Quetzalcóatl, a cultured nation of the Toltecs, when the proof is of the strongest, that every one of these is an absolutely baseless fiction of mythology? Let it be understood, hereafter, that whoever uses these names in an historical sense betrays an ignorance of the subject he handles, which, were it in the better known field of Aryan or Egyptian lore, would at once convict him of not meriting the name of scholar. ${ }^{88}$

\section{Pure mythologie?}

Jill Leslie Furst dans son étude des codex de la Mixteca considérés sérieusement par Alfonso Caso comme documents historiques et généalogiques, avance l'hypothèse selon laquelle les codex généalogiques Mixtèques qui placent souvent Quetzalcóatl comme ancêtre dynastique, n'auraient aucune valeur chronologique historique, et qu'il s'agit en fait de récits mythiques à valeur divinatoire:

The numerous dates in the Mixtec codices and lienzos have long been considered a mean of reconstructing Mixtec prehistory..... My own study of the obverse of Vindobonensis, suggest, however, that none of the dates in this important and exceptionally well painted manuscript may be read as a literal and historical indicator of time. ${ }^{89}$

de México-Instituto de Investigaciones Filológicas, 2003), II4, citant Tomás López Medel, Relation, Papers of the Peabody Museum of American Archaeology and Ethnology, vol. XVIII, Apendix B (Cambridge and Massachusetts: Harvard University, 194I, 194).

88. Brinton, American Hero Myth, 35 .

89. Furst, "The year I Reed, Day I Alligator: A Mixtec Metaphor», 93. 
Nous pouvons tomber partiellement d'accord sur le peu de fiabilité historique des généalogies anciennes représentées sur ces documents, dont les auteurs, comme c'est de tradition humaine, ont embelli, anobli et divinisé leur passé. Les généalogies royales issues de Quetzalcóatl n'ont d'autre valeur que celle de justifier une royauté de droit divin, mais cela ne signifie pas pour autant que les dates inscrites n'aient aucune valeur du point de vue de l'astronomie et de la chronologie historique, comme aussi d'ailleurs, des points de vue de la philosophie, de la religion et de l'histoire des sciences et de la politique.

Graulich, auteur majeur et d'une immense maîtrise de l'histoire et de la culture de l'ancienne Mésoamérique revient à diverses reprises sur la figure de Quetzalcóatl..$^{\circ}$ Il rappelle dans Mythes et rituels du Mexique ancien prehispanique, ${ }^{\text {9I }}$ que jusqu'à la fin du XIx ${ }^{\text {ème }}$ siècle, c'est à peine si l'on doutait de l'historicité de Quetzalcóatl et des Toltèques. Graulich évidemment ne croit pas beaucoup à l'historicité du personnage:

Une tentative de biographie de Quetzalcóatl, le soi-disant roi et réformateur religieux des prédécesseurs des Aztèques, les Toltèques, a conduit à une conclusion sans ambigüité: tel que présenté par les sources, ce Quetzalcóatl est mythique de part en part. Peut-être un personnage de ce nom a-t-il existé, mais on ne sait rien de sa vie ni des événements de son temps, Rien. Le mythe a tout recouvert. ${ }^{92}$

Il va plus loin encore, lorsqu'il écrit que:

Il est significatif qu'après la Conquête les anciens Mexicains ont cru bon de s'inventer un souverain pseudo-historique, le fameux Quetzalcóatl, le Serpent à Plumes, qui aurait interdit les sacrifices humains... ${ }^{93}$ Or selon les chroniques, Quetzalcóatl aurait été un réformateur religieux quasi monothéiste qui aurait interdit les sacrifices humains et que son frère ennemi, Tezcatlipoca, partisan des sacrifices aurait chassé de la ville. Il serait parti vers l'est et l'on croit retrouver sa trace... à Chicchen Itza! Belle illustration de la prudence qui doit présider à la lecture des sources écrites. Toutes sont postérieures à la conquête espagnole et

90. Graulich, Myths of Paradise Lost in Pre-Hispanic Central México; Graulich, Quetzalcóatl y el espejismo de Tollan; Graulich, Los reyes de Tollan.

9I. Graulich, Mythes et rituels du Mexique ancien prehispanique (Bruxelles: Académie Royale, 1987).

92. Graulich, Montezuma ou l'apogée et la chute de l'empire aztèque, introd., V.

93. Graulich, Le sacrifice humain chez les Aztèques, I5. 
certaines s'efforcent, de manière compréhensible, de présenter aux colonisateurs et aux missionnaires une image plus flatteuse de leur passé. En l'occurrence, il s'agissait de montrer que les indiens aussi avaient à certains moments réprouvé les sacrifices humains. ${ }^{94}$

Enfin:

no se puede reconstruir el pasado con meras enumeraciones de lugares o de ciudades conquistados, incluso aunque las listas concordaran entre sí, lo que no es el caso. Tampoco se puede reconstruir el pasado con listas de reyes fantasmas de quienes no se sabe nada.95

Ici, Graulich non seulement nie l'existence historique de Quetzalcóatl roi de Tollan et de Tollan elle-même, mais il va même jusqu'à prétendre qu'un aspect aussi important de sa légende que celui de refuser les sacrifices humains serait une affabulation des indigènes pour complaire au conquérant chrétien. Autant j'approuve la première proposition, autant je ne puis être d'accord avec la seconde, et reste persuadé que ce trait du personnage est authentiquement préhispanique. Mendieta le prouve, les aspirations à se libérer des sacrifices si douloureux étaient bien présents dans le Mexique préhispanique, et les indiens Totonaques, suppliaient leur grande déesse, parèdre du Soleil, de les en épargner:

Tenían gran esperanza en ella que por su intercesión les había de enviar el sol a su hijo para librarlos de aquella dura servidumbre que los otros dioses les pedían de sacrificarles hombres, porque lo tenían por gran tormento, y solamente lo hacían por el gran temor que tenían a las amenazas que el demonio les hacía y daños que de él recibían. ${ }^{96}$

Les indiens eux-mêmes étaient épouvantés par les sacrifices, ils ne les pratiquaient que pour complaire aux dieux mauvais, et s'en protéger. C'est du moins ce qu'il ressort de la déclaration faite par la première ambassade de Moctezuma aux espagnols:

94. Graulich, Le sacrifice humain chez les Aztèques, I8-I9.

95. Graulich, Le sacrifice humain chez les Aztèques, IоI.

96. Mendieta, Historia eclesiástica indiana, 89. 
Luego al día siguiente enviaron aquellos seńores y capitanes tres clases de cosas en presente a Cortés; y los que la trajeron le decían: «Señor, veis aquí cinco esclavos: si sois dios bravo, que coméis carne y sangre, comeos éstos y traeremos más; si sois dios bueno, he aquí incienso y pluma; si sois hombres, tomad aves, pan y cerezas. ${ }^{97}$

La proposition de Graulich selon laquelle le refus des sacrifices dans les traditions préhispaniques de Quetzalcóatl serait une complaisance à l'égard des chrétiens est d'autant plus surprenante qu'il a été l'un des plus engagé à démontrer que lorsque l'on observe des ressemblances frappantes entre la religion aztèque et la chrétienté, il ne faut pas conclure immédiatement à un emprunt d'époque coloniale: «En Amérique, les chercheurs actuels, plus guère formés au comparatisme religieux, ont tendance à croire que tout ce qui ressemble au christianisme dans les religions méso-américaines est d'influence européenne, ce qui n'est évidemment pas le cas». ${ }^{8}$ Pourtant, à propos d'un autre trait concernant Quetzalcóatll, Graulich n'hésite pas à inverser de nouveau les termes de ce que les sources attestent pourtant de manière répétitive, Quetzalcóatll était blanc, avait la peau claire. Graulich écrit:

parce qu'en I519 Hernan Cortes fut pris pendant un temps pour le dieu qui revenait, les moines espagnols crurent que Quetzalcóatl avait dû être un Blanc venu évangéliser les Indes occidentales et les indiens s'empressèrent de leur emboiter le pas et de présenter Quetzalcóatl comme un réformateur qui aurait interdit les sacrifices humains. ${ }^{99}$

La blancheur de la peau en Amérique comme en Europe et bien d'autres endroits, Indes, Japon, est une des marques physiques de l'appartenance à la classe supérieure. Non pas pour des raisons de race, Brinton affirme que cette croyance vient du fait que la clarté de la peau reflète celle de la lumière que l'on a adorée partout comme divine et céleste. ${ }^{100}$ Mais il se peut plus simplement que ce soit parce que cela dénote une personne n'ayant pas besoin de travailler aux champs sous le soleil. Et tout comme les nobles d'Europe se faisaient

97. López de Gomara, Historia de las conquistas de Hernan Cortés (México: imprenta de testamentaria de Ontiveros, I826), cap. 45, p. 80.

98. Graulich, Le sacrifice humain chez les Aztèques, 45. voir Aussi Graulich, «Myths of Paradise Lost in Pre-Hispanic Central México» et Graulich, «L'arbre interdit du paradis aztèque».

99. Graulich, Le sacrifice humain chez les Aztèques, 33.

Ioo. Brinton, American Hero Myth. 
un devoir de se garder du soleil, les grandes dames surtout, on disait de Moctezuma qu'il était de peau claire comme aussi sa fille Isabelle. Qu'on le veuille ou non, que cela plaise ou non, à part quelques exceptions, la blancheur de la peau est appréciée un peu partout, dans les caraïbes comme au Japon: «La gente de estas islas es más blanca y dispuesta que la de Cuba ni Haití, especial las mujeres, por cuya hermosura muchos hombres de Tierra-Firme, como es la Florida, Chicora y Yucatán, se iban a vivir a ellas». ${ }^{\text {Ior }}$ De plus et surtout, les rapports des blancs, des albinos avec la vie recluse et le sacrifice sont bien attestés au Mexique comme ailleurs en Amérique: «cuando no llovia arrojaban a los nacidos blancos, y que de puro blanco no ven». ${ }^{102}$ En vérité, tout ce qui touche à Quetzalcóatl est bien compliqué! La position franchement déclarée en faveur de l'explication mythologique de Graulich avait été celle aussi de Brinton qui refusait le titre de savant à qui voudrait faire de Quetzalcóatl un personnage historique et de Tollan une ville terrestre réelle. Pour Brinton, Tollan est la ville du soleil resplendissant et de la lumière. ${ }^{103}$ Il veut interpréter chaque détail selon cette clef unique du combat du jour et de la nuit, de la lumière et des ténèbres au point de lasser le lecteur. Je ne puis évidemment accepter cette interprétation astrale de la mythologie mésoaméricaine qui sera celle aussi d'Eduard Seler et d'autres auteurs. Brinton voit tout solaire en Quetzalcóatl, Seler y voit par contre la lune, ${ }^{104}$ on ne s'y retrouve pas très bien. S’il y a bien une relation forte entre Quetzalcóatl et les lois du ciel, les astres, elle n'est pas aussi simple ni aussi confuse. Avec Michel Graulich et la plupart des auteurs les plus récents l'école mythologique a semble-t-il enfin gagné la partie, bien qu'il se trouve là aussi quelques abus. Nous avons vu que Graulich fait de certains aspects de Quetzalcóatl, comme par exemple la blancheur de sa peau et sa barbe, les signes d'une invention d'après la conquête, mais Werner Stenzel avance plus loin encore dans son livre «Mitogenesis de una leyenda postcortesiana». ${ }^{105}$ Pour lui, à peu près tout ce que l'on sait de Quetzalcóatl aurait été inventé après l'arrivée des blancs. Il croit aussi qu'il est possible de

IOI. Francisco López de Gomara, Historia de las Indias. Historiadores primitivos de las Indias Occidentales, t. I (Madrid: s.e., I749), cap. XLI, 31.

I02. Tezozómoc, Crónica mexicana, LXXII, El sacrificio humano, 309; Yólotl González, El sacrificio humano, 256.

I03. Brinton, American Hero Myth.

I04. Seler, 1993: IV: 165-I75.

I05. Werner Stenzel, "Mitogénesis de una leyenda postcortesiana», Cuadernos del Unicornio, nr. I3 (Nuevo León: Universidad Autónoma de Nuevo León-Facultad de Filosofía y Letras, 199I). 
séparer le dieu Serpiente Emplumada Viento du héros historique Topiltzin Ce Acatl Quetzalcóatll de Tula. J'apprécie la documentation et suis disposé à écouter les arguments dont certains semblent intéressants, et même convaincants, mais il va sans dire que je ne puis accepter cette hypothèse en général. D’ailleurs, nous avons de Torquemada citant Sahagun une notice qui démontre sans faute que les indigènes croyaient vraiment que les espagnols étaient de retour de Tlilan Tlapalan. Pour eux, Tlilan Tlapalan était un lieu mythique, très loin, de l'autre côté de l'océan, mais ils étaient bien en peine de savoir où exactement. Aussi demandent-ils aux espagnols s'ils peuvent leur dire où se trouve Tlilan Tlapalan. Les espagnols éberlués ne savent bien sûr quoi répondre puisqu'ils ne connaissent encore rien de ces légendes locales:

Y dice el Padre Fr. Bernardino de Sahagún, que en la ciudad de Xuchimilco, le preguntaron algunos indios, qué donde era Tlapallan? Y que les respondió, que no sabía, ni tampoco entendió el intento de la pregunta; porque aún no sabía estas cosas, porque fue cincuenta ańos antes que lo escribiera, que vino a ser a mui pocos años, después de su conversión, y entrada del evangelio, en estas tierras; y dice más, que entonces ellos andaban dando tientos, para ver si nosotros los Religiosos, y Españoles sabíamos algo de aquellas antiguallas, que ellos tenían. ${ }^{106}$

\section{Solutions de compromis}

D'autres auteurs essaient de ménager la chèvre et le chou. Laurette Séjourné voit en Quetzalcóatl la figure centrale de toute la spiritualité de Mésoamérique. Un roi de Tollan-Teotihuacan qui aurait prêché l'union mystique avec la divinité pour sauver l'homme de son alourdissement dans la matière, par une vie d'ascèse et d'abstinence. En somme un ermite, un renonçant, un grand prophète, historique, mais quasi divin. Nous sentons ici, bien sûr, un christianisme profondément ancré chez l'auteur de ces lignes. On a du mal à comprendre la justification de considérations d'ordre éthique telles que ce commentaire à propos du serpent à plume de la façade du temple de Xochicalco: «El Quetzalcóatl es el signo del advenimiento de la consciencia». ${ }^{107}$ Cette attitude spiritualiste et très émotive aura bien évidemment provoqué chez certains lecteurs

Io6. Torquemada, Monarquia indiana, VI: XXIV; II: 50: I.

I07. Séjourné, El Universo de Quetzalcóatl, 38, fig. 31. 
à prétentions scientifiques un rejet immédiat et viscéral. Laurette Séjourné, de toute évidence, a projeté sur Quetzalcóatl ses propres aspirations idéalistes et absolues. Je trouve moi-même les textes quasi mystiques de Laurette Séjourné plutôt littéraires et charmants, très engagés idéologiquement et autobiographiques, autrement dit en dissonance avec ce que l'on attend d'une analyse scientifique. Mais justement pour cela, parce que la culture mésoaméricaine est toute littérature, exaspération religieuse et convention, mise en forme des émotions et des passions, passion mystique, je crois que cet auteur, en dépit de ses égarements, est bien plus près de la vérité qu’on ne le juge généralement:

Esto sugiere, posiblemente, la llegada al mundo del conocimiento interior cuya gestación requiere - según el ejemplo del rey de Tula - toda una existencia [...]

Como la existencia del rey de Tula termina también en una ruptura del orden natural, resulta que su historia no es más que una réplica, sobre un plano diferente, de la del reptil en su voluntad de superación. En los dos casos, la meta es alcanzada por medio de largos esfuerzos simbolizados por el movimiento - peregrinación del primero; tentativas de erguirse del segundo - así como por el sacrificio de la forma original. De ahí que, lo mismo que la materia bruta está considerada a partir de la toma de consciencia de una posible liberación de los límites físicos, la sustancia de la serpiente emplumada lo es a partir de su visión de un dominio que trasciende la objetividad, de la visión que insufla la necesidad de dirigirse 'a los confines del mundo, hacia el horizonte donde cielo y tierra se unan'.

El mito marca ese punto de partida con los remordimientos del pecado carnal que abre la historia de Quetzalcóatl. Como ésta acaba con la hoguera, su vida se revela entonces limitada al peregrinaje, a la búsqueda de un más allá de la situación experimentada corporalmente.

La soberanía de que es investido Quetzalcóatl desde antes que existiera el reino de Tula - ya que como hemos visto, el reino implica siempre una previa divinización y que ésta, a su vez, implica un rey poseído del deseo de transformación - queda establecida sobre el dominio de los vastos espacios que separan la inercia animal de la consciencia pura. Es, pues, en esta hazaña interior donde reposa la soberanía que originó el reino de los grandes artistas, de los hombres que, al igual que su dios, poseían el secreto de convertirse en energía luminosa. Es decir, que lo que hace de Quetzalcóatl un rey, es su determinación de cambiar el curso de su existencia, de iniciar una marcha a la cual no lo obliga más que una necesidad íntima. Él es el Soberano porque obedece a su propia ley, en lugar de obedecer a la de otros. ${ }^{108}$ I08. Séjourné, El Universo de Quetzalcóatl, 55-56. 
J'ai cité largement ce fragment parce qu'il est typique de l'écriture de Laurette Séjourné, une écriture passionnelle, militante, qui se laisse emballer dans ses propres visions et convictions, projette ses propres espérances: Él es el Soberano "porque obedece a su propia ley». Tout un programme politique et messianique d'anarchie militante et intégriste! Elle se trompe lorsqu'elle croit que Quetzalcóatl est un personnage historique. Elle se trompe encore lorsqu'elle en fait un surhomme maître et créateur de son propre destin, libre et que personne n'oblige, un révolutionnaire messianique. Mais elle touche juste lorsqu'elle pose au cœur de la problématique de Quetzalcóatl le dépassement de la matière et de l'inertie animale, la sublimation lumineuse des limitations terrestres, la transcendance artistique. Pourtant, ce n'est pas un personnage historique, isolé et unique qui porte tout cela par nécessité intime, c'est la base culturelle, philosophique et religieuse de tout l'ensemble culturel de Mésoamérique. Et Quetzalcóatl n'en est que le meilleur représentant, mais un représentant littéraire et scénique. Et sa seule liberté est d'accepter le destin tragique qui lui est imposé, par force. Mais ce fragment tombe à point pour notre interprétation: «su vida se revela entonces limitada al peregrinaje, a la busqueda de un más allá de la situación experimentada corporalmente». ${ }^{109}$ Séjourné s'est laissée emporter par son enthousiasme, et c'est pour cette raison même qu'elle touche juste, les cultures mésoaméricaines étaient marquées de la même faiblesse. Et d'ailleurs, dans sa revue critique des idées de Laurette Séjournée, Michel Graulich présente un avis assez proche:

A decir verdad, la autora no se enreda demasiado con referencias bibliográficas. Pero he demostrado anteriormente y veremos de nuevo en este libro que la idea de la materia de la que uno tiene que liberarse para acceder a la deidad suprema sí está en el centro del pensamiento religioso mexicano y del sistema sacrificial en particular. ${ }^{\text {II }}$

Ou encore:

l'idée du sacrifice comme un instrument de libération de l'âme prisonnière de la matière, thème ancien de l'Inde, des pythagoriciens et des néopythagoriciens, des philosophes chinois après Confucius et de la gnose notamment, était bel et

I09. Séjourné, El Universo de Quetzalcóatl, 55-56.

IIO. Graulich, Quetzalcóatl y el espejismo de Tollan, 22-23. 
bien un thème mésoaméricain et Laurette Séjournée a le grand mérite d'avoir été la première à le pressentir, sinon à le démontrer». ${ }^{\mathrm{II}}$

Bien plus tard, Emanuela Mónaco verra aussi l'aspect de transfiguration, de sublimation du destin de Quetzalcóatl: "Quetzalcóatl lleva a cabo su transformación de una vida humana corruptible, deleznable, a una vida celeste incorruptible, inmortal». ${ }^{\text {I2 }}$ Position bien proche de celles de Laurette Séjournée et Michel Graulich, et très bien justifiée, à mon sens. Cette tradition et ces textes reflèteraient une expérience mystique, un parcours initiatique.

En faveur d'un personnage historique mais fortement sceptiques et critiques, se déclarent des auteurs tels que Eloise Quinones Keber, ${ }^{\mathrm{II}}$ David Carrasco $^{\text {II } 4}$ et Hanns Prem. ${ }^{\text {IIs }}$ David Carrasco, comme Eloise Quinones Keber, voit en Quetzalcóatl un modèle de la royauté et admet un personnage historique qui s'en serait inspiré ou incarné. Hanns Prem veut bien accepter l'historicité de Quetzalcóatl, et de Tollan, mais se montre très prudent et accepte qu'une quantité de légendes ont brouillé l'image.

Plus froidement, Victoria Solanilla résume les avis contradictoires pour les accepter tous ensemble:

La figura de Quetzalcóatl presenta un alto grado de dificultad para su estudio, ya que las modernas investigaciones han llegado a concluir que no solamente fue un personaje histórico concreto sino que también fue un dios, un concepto, un arquetipo que se repite en las diversas etapas y zonas culturales de Mesoamérica. ${ }^{116}$

Cette position largement ouverte est sans doute bien proche de la vérité, mais ne résout pas la question pour autant, et en fait, n’apporte rien.

III. Graulich, Le sacrifice humain chez les Aztèques, 34.

II2. Mónaco, "Quetzalcóatl de Tollan», I39.

I13. Eloise Quiñones Keber, «Topiltzin Quetzalcóatl in text and images», M.A. thesis (New York: Columbia University Press, 1979).

II4. David Carrasco, Quetzalcoatl and the Irony of Empire: Myths and Prophecies in the Aztec Tradition (Chicago: University of Chicago Press, 1983).

II5. Hanns Prem, Los reyes de Tollan y Colhuacan, "Los reyes de Tollan y Colhuacan», Mexico, Estudios de Cultura Náhuatl, nr. 30 (I999): 23-70.

II6. Victoria Solanilla Demestre, "Quetzalcóatl y su proyección en el Cristianismo», in Lo que duele es el olvido (Barcelona: Universitat de Barcelona, 1998), 83-93. 


\section{Un modèle des funérailles royales}

Sous la plume de Patrick Johansson nous trouvons des travaux de l'école structuraliste française teintés de phénoménologie et de brillantes intuitions poétiques. Johansson revient à plusieurs reprises sur les significations possibles de Quetzalcóatl. Son article «La mort de Quetzalcóatl: un modèle exemplaire pour les obsèques des seigneurs mexicains $\nu^{117}$ reprend de nombreux arguments exposés dans le livre Ritos mortuarios nahuas precolumbinos ${ }^{\text {II8 }}$ qui offre une interprétation originale, et elle aussi exemplaire, de ce qu'il nomme le mythe de Quetzalcóatl, affirmant par là son caractère non-historique, son caractère de modèle religieux. Modèle, selon lui, des funérailles royales en Mésoamérique et qu'il nomme aussi La ley de Topiltzin. Cette interprétation est certainement soutenue et confirmée entre autres nombreux exemples par les texte de Tezozómoc et Durán à propos de l'habillage du corps du roi défunt pour les obsèques de Tizoc: «Hecho esto y cantando delante del, le tornan a descomponer y le adornan de los vestidos que llaman de Quetzalcóatl. ${ }^{\text {II9 }}$ El cuarto vestido que le ponían era del dios Quetzalcóatl, ponianle en la caueca una máxcara de tigre con un pico de pájaro». ${ }^{120}$

C'est dire qu'il entend le mythe de Quetzalcóatl comme le modèle littéraire de la liturgie des obsèques d'un monarque. La procession des funérailles royales depuis la préparation et l'exposition du corps jusqu'au bûcher deviennent la fuite de Quetzalcóatl vers l'autre monde. Ce faisant, son interprétation se situe ici au plus près de la mienne. Pour lui il s'agit d'un texte mythologique servant de modèle au rituel d'accompagnement vers l'autre monde du souverain défunt. Dans la mesure ou les funérailles en général, et les funérailles nationales, royales ou impériales en particulier sont organisées selon un protocole et une pompe parfaitement théâtrale, nos deux interprétations se rejoignent, et s'accordent en parallèle sur beaucoup de points. Encore faut-il savoir de quel roi nous parlons. Un vrai roi? Son modèle céleste? $\mathrm{Ou}$ son substitut rituel? Lorsqu'un roi se meurt, son successeur peut bien l'accompagner vers l'au-delà, en la personne de son substitut, de son alter ego, de son ixiptla, ce qui permet bien entendu au nouveau roi de détourner la mort

II7. Johansson, «La mort de Quetzalcóatl».

II8. Patrick Johansson, Ritos mortuarios nahuas precolumbinos (Puebla: Secretaría de Cultura de Puebla, 1998).

I19. Tezozómoc, Crónica mexicana, LXII, 200I: 264.

I20. Durán, Historia de las Indias de Nueva España, I: XXXIX: 355. 
de sa propre personne. Le sacrifice qu'il offre est expiatoire et de protection, et fait partie des cérémonies d'intronisation. La lecture de Patrick Johansson est des plus intéressantes, et de nombreux aspects viennent l'appuyer. Le roi était peut être malade avant d'en mourir, il avait bien mauvaise mine, les yeux creux, ou tout gonflé. Effectivement, on l'a sans doute fait boire pendant l'agonie, on grime et masque le mort comme on le fait avec Quetzalcóatl, on lui sacrifie une ou plusieurs épouses pour l'accompagner, ainsi que ses gens de service, ses pages, nains et bossus qu'il aime tant. On va chanter ses exploits et rappeler tous les lieux qu'il a visité, sanctifié, où il s'est illustré et laissé des souvenirs durables, enfin, richement habillé et décoré, le visage couvert d'un masque on le place sur le bucher. A peu près tout est parallèle et l'hypothèse d'un Quetzalcóatl comme modèle des funérailles royales doit emporter l'adhésion. Mais ce n'est là que l'une des applications du mythe de Quetzalcóatl, d'autant que la solution de Patrick Johansson génère aussi quelques énigmes. Selon lui, la mort de Quetzalcóatl a bien lieu à Tollan, dans le palais même du roi. Tout d'abord Tezcatlipoca l'oblige à se regarder dans le miroir, autrement dit, Quetzalcóatl serait mort en se regardant dans le miroir de Tezcatlipoca, en quelque sorte il serait passé de l'autre côté du miroir, dans l'autre monde. C'est une idée assez alléchante, mais je ne puis être d'accord avec cette interprétation, ou du moins seulement de manière partielle. Plus loin, c'est dans l'acceptation du pulque qu'il propose de voir le moment de la mort: «Dans l'optique qui est la nôtre, l'entrée de Tezcatlipoca dans la maison de Quetzalcóatl représente la mort de ce dernier, mort attendue puisque le roi était vieux et malade, et le médicament qu'on lui propose sera en fait le remède mortel qui guérira son agonie». ${ }^{21}$

«Le fait d'accepter la boisson enivrante que lui propose Tezcatlipoca constitue une rupture de pénitence, équivalent actanciel, dans le contexte considéré, de la mort». ${ }^{122}$

Quetzalcóatl serait-il donc mort empoisonné? De coma alcoolique? ivremort! Ici non plus, je ne puis suivre cette lecture, bien qu'elle soit elle aussi acceptable d'une certaine manière, remise dans un autre contexte. Le miroir présente et annonce la mort, il n'est pas encore la mort. Le pulque constitue aussi certainement un signe de la mort qui s'approche, mais il n'est pas encore la mort, lui non plus, le Rabinal Achi l'exprime très clairement: Concédeme tu

I2I. Johansson, La mort de Quetzalcóatl, I8.

I22. Johansson, La mort de Quetzalcóatl, 2I. 
alimento, tus bebidas. Las recibiré para probarlas». Esto dijo tu voz. "Ésa será la suprema señal de mi muerte, de mi fallecimiento». ${ }^{123}$

La troisième annonce de la mort est constituée par la nuit d'ivresse avec Quetzalpetlatl. C'est encore le Baron de los Quichés qui nous en assure:

Concedeme a la Madre de las plumas, la Madre de los Verdes Pajarillos, la Piedra Preciosa, traída de Tzam-Gam-Garchag, cuyos labios están aún por estrenar, cuya cara no ha sido tocada, para que estrene su boca, que estrene su cara. Que baile con ella, que yo la muestre en los vastos muros, en la vasta fortaleza, en los cuatro rincones, en los cuatro lados, como suprema seńal de mi muerte, de mi fallecimiento, bajo el cielo, sobre la tierra. El cielo, la tierra, estén contigo, jefe Cinco-Lluvia. ${ }^{\mathrm{I} 2}$

Et pour finir, pour Quetzalcóatll comme pour le Baron des Quichés, cette mort ne sera pas simplement symbolique, un simple équivalent actanciel, une forme littéraire, non, ce sera vraiment la mort, la mort clinique. ${ }^{125}$ Si dans son ensemble l'interprétation de Johansson est très convaincante pour la partie du texte allant de la mise dans la caisse de pierre jusqu’à la crémation à Tlilan Tlapalan, elle n'explique pas les singularités de la première partie, celle de la vie de renoncement et de pénitence jusqu'à l'acceptation du miroir, de la coupe et de la nuit d'ivresse. Pour cette partie, chacun des arguments est à étudier en détail, et si l'on y trouve des propositions très intéressantes, on y remarque aussi quelques incohérences, quelques impossibilités logiques. La présentation du miroir peut bien signifier la porte d'entrée dans le monde des esprits. C'est pour cela que l'on voile les miroirs dans la maison du mort en Europe comme en d'autres pays. La boisson enivrante est un signe de mort. En boire cinq coupes, justement, signifie au Mexique se saouler à mort! La nuit d'amours avec une prostituée qu'elle soit ou non sacrée peut elle aussi mener à une sorte de petite mort. Evidemment que le départ, et le voyage, en général sont les images du grand voyage par excellence, du voyage vers l'au-delà ou déjà dans l'autre monde. Comme chez nous le chemin de Santiagio de Compostelle, sur terre et dans la voie lactée. Le texte des Annales de Cuauhtitlan comme

I23. Rabinal Achi, Teatro indígena prehispánico, Francisco Monterde, prol. (Ciudad de México, Universidad Nacional Autónoma de México, 2015), 68.

I24. Blixen, «Rabinal Achi», 72.

I25. Bien que celle-ci dans la pièce de Rabinal soit jouée de la manière la plus légère qui soit. 
les autres textes qui lui sont parallèles sont bien explicite, le voyage vers TlilanTlapalan est un exil ou un pèlerinage vers le bûcher funéraire dans lequel Quetzalcóatl va se jeter ou se faire jeter pour devenir l'Etoile du Matin d'une nouvelle ère, d'un nouveau Soleil. L'innovation chez Patrick Johanson c'est de situer le moment de la mort bien plus tôt:

En fait deux lectures du mythe qui se compénètrent peuvent être faites ici. La première, la plus accessible, et que le texte exprime de manière explicite en structure de surface, établit que Quetzalcóatl part de Tula, chassé par Tezcatlipoca, et s'en va mourir à Tlillan, Tlapallan, un lieu situé sur la côte du Golfe du Mexique. L'autre plus sémiologique, moins évidente, et qui constitue notre hypothèse, serait: que Quetzalcóatl meurt à Tula à un moment précis que notre analyse déterminera, et que son voyage vers Tlillan Tlapallan s'effectue d'Ouest en Est dans les entrailles régénératrices du Mictlan. La mort, le départ, le voyage et l'arrivée constitueraient dans ce cas le modèle exemplaire du parcours eschatologique effectué par un roi après son décès. ${ }^{126}$

L'idée présente ici d'une double lecture est bien intéressante et peut être développée. On pourrait ainsi tracer plusieurs histoires parallèles toutes entrelacées:

- Le récit d'une vie se terminant à Tollan dans la caisse de pierre.

- Celui d'une vie se terminant par l'exil ou la fuite et un suicide à Tlilan Tlapalan.

- Le récit du voyage en esprit dans le monde inférieur.

- Le thème mythique de l'incarnation, de la mort et de la renaissance du dieu.

- Le modèle structural des rites d'initiation.

- Le rituel d'intronisation royale.

- L'image de la tragédie de l'homme et de ses espérances.

- L'éternel recommencement des cycles cosmiques, plus particulièrement ici celui de Vénus.

- Le cortège funéraire transportant le corps du roi de son palais au bûcher de crémation.

Effectivement, durant les funérailles on déclamait et jouait la vie et les faits hérö̈ques du défunt et on allait en pèlerinages visiter les lieux où il était passé de son vivant. On pouvait y promener en procession son corps bandé, ou

I26. Johansson, La mort de Quetzalcóatl, I2. 
son image, ou encore les cendres et restes du roi défunt mais on pouvait tout autant se contenter de déclamer les hauts faits de sa vie, ou les deux parallèlement, un acteur mimant les hauts faits déclamés de la vie du roi. On rejouait sa vie. Nous voyons donc ici la possibilité d'une composition polyphonique dans laquelle on joue la même partition simultanément ou consécutivement mais chaque partition est décalée par rapport aux autres, déplacée à l'octave, à la quinte, ou sur une autre clef, et l'on reprend le thème de base alors que d'autres ont déjà commencé une autre partie ou d'autres variations. On peut alors accepter que l'interprétation proposée ici et celle de Patrick Johnson, bien que différentes, ne soient pas nécessairement contradictoires.

Pour Patrick Johansson, ce texte des Annales de Cuauhtitlan et le mythe sur lequel il se fonde constituent le modèle des funérailles royales, funérailles qui constituent elles aussi, très évidemment, une sorte de représentation théâtrale:

Le voyage de Quetzalcóatll vers Tlillan, Tlapallan ne représente pas seulement l'exil du roi de Tula et la régénération cosmique du soleil mais constitue également le modèle exemplaire de la régression du défunt dans le Mictlan et la gestation de son âme, modèle qui établit en fait la «loi de Topiltzin» c'est-à-dire le protocole rituel correspondant aux funérailles d'un seigneur mexicain. ${ }^{127}$

Il écrit d'ailleurs: «Les différents programmes narratifs entrelacés dans cette version ne s'opposent pas en termes d'exclusion. Comme nous l'avons indiqué plus haut, la fusion dans une totalité cognitive des différents niveaux actanciels est une nécessité pour une appréhension fonctionnellement vécue du sens». ${ }^{128}$

Le rite sacrificiel de la représentation théâtrales du mystère de Quetzalcóatl est aussi une transposition des funérailles du souverain, chacun des deux étant l'ixiptla de l'autre sans que l'on puisse donner la primeur à l'un plutôt qu'à l'autre, et les deux sont aussi les ixiptla du mythe fondateur de la mort du dieu, mythe qui lui-même ne peut être considéré comme premier, mais plutôt comme description visuelle de la pièce représentée. Et encore, une pièce dans laquelle se réduit à l'essentiel la tragédie humaine. Nous étions accoutumés à considérer le terme ixiptla comme limité à des personnages, des animaux, des objets, des éléments naturels ou des concepts, mais nous voyons ici la possibilité d'étendre cette notion à des fragments historiques, rituels et mythiques complexes, des séquences narratives

I27. Johansson, La mort de Quetzalcóatl, Iо.

I28. Johansson, La mort de Quetzalcóatl, Iо. 
très élaborées, des structures littéraires entières, transposées dans le temps et l'espace, rhabillées, réinterprétés. Ce qui est parfaitement illustré par les récits historiques ou pseudo-historiques calqués sur des modèles mythiques, eux-mêmes se répétant en séries de variantes à partir d'une même structure et transposées sur le même échiquier du temps réglé par séquences de 52 ans. ${ }^{229}$

Il serait bien temps d'ouvrir ici une parenthèse pour essayer de cerner les sens possibles de ce mot essentiel pour la compréhension des cultures mésoaméricaines préhispaniques et de la culture Nahua en particulier, celui d'Ixiptla. Ixiptla est construit sur la racine Xipe qui signifie écorcher la peau, dépecer, c'est à dire arracher l'apparence, l'image, la partie visible, extérieure de l'être. L'ixiptla dans le sens étroit, est un être humain qui représente un dieu sur terre lors des cérémonies, un acteur, mais cet acteur disparait complètement pour n'être plus qu'une enveloppe, une baudruche, une peau que va gonfler le souffle du dieu, littéralement se mettre dans sa peau, se mettre à sa place, c'est-à-dire faire prendre des vessies pour des lanternes. Graulich le dit bien Le système sacrificiel n'est-il d'ailleurs pas par excellence celui des substitutions? ${ }^{\text {?30 }}$ L'ixiptla devient dieu, il est le dieu lui-même, présence de dieu. L'ixiptla permet au dieu de se matérialiser, de s'incorporer, de s'incarner, de se figurer, de se transfigurer, de s'actualiser, de se vêtir, de s'habiller, de se présenter, de se représenter, de se montrer, de paraître, d'apparaitre, de naître, de connaître, de se faire connaître et reconnaitre, de se manifester, d'exister. Ce que fait l'ixiptla du dieu, une fois devenu dieu, le fait ensuite celui qui, portant sa peau, va le représenter à nouveau sur terre, son Xipe (xipe Totec), mot lui aussi apparenté. Tout ce qui peut représenter un autre ou autre chose est ixiptla. Le fils est l'ixiptla de son père, l'ambassadeur est l'ixiptla de son roi, la statue est l'ixiptla du dieu, la montagne miniature de pâte d'amarante est l'ixiptla de la vrai montagne, le temple miniature l'ixiptla du temple principal, une situation historique rappelant une séquence mythique en constitue aussi l'ixiptla, le personnage couvert de la peau d'une victime sacrificielle représentant un dieu est ainsi l'image d'une image. Ce dieu lui-même étant la représentation d'une force naturelle, image du vent, de la pluie, etcetera. En fait le monde entier n'est constitué que d'un réseau de chaînes d'ixiptla, tous reflets les uns des autres. La note 24 au texte de Cristobal del Castillo,

I29. Michel Graulich a présenté une étude des variations du mythe dans Quetzalcóatl y el espejismo de Tollan.

I30. Michel Graulich, Le sacrifice humain chez les Aztèques, 88. 
Historia de la venida ${ }^{131}$ traduit Ixiptla comme personage teatral, pour être originale, cette traduction tombe ici au mieux. C'est très bien vu.

Il me semble très possible que lors des représentations théâtrales ce voyage ne durait qu'un instant, et qu'après son départ, sa sortie de scène, seul un entracte musical déclamé par un chœur et des danses séparait le décor de scène du palais de Tollan de celui de l'arrivée à Tlilan Tlapalan, ce décor pouvait être réduit à sa plus simple expression et le changement de lieu pouvait être simplement déclaré comme tel. Le bûcher de crémation pouvait être représenté par un simple brasero dans lequel on jetait du copal pour faire s'élever un nuage d'étincelles et de fumée. Le voyage était parfois conté et mimé sur place. Miguel Léon Portilla le mentionne: «Una vez más el coro y el actor principal van alternando los himnos. Se vuelven a describir los sitios por donde va pasando Quetzalcóatll en compañía de los toltecas». ${ }^{132}$

Nous voyons d'ailleurs que ce long et grand voyage ne se pouvait faire qu'en esprit puisque Tollan et Tlillan Tlapalan sont un seul et même lieu. Selon Sahagun, lorsque Quetzalcóatl demande au vieux où il doit aller, celui-ci répond à Tollan Tlapallan: «O viejo, a donde me tengo de yr: y le dixo, el dicho viejo. Por fuerça aueys de yr, a Tullan Tlapallan». ${ }^{133}$ Ce qui pourrait être pris pour un lapsus de Tlillan Tlapallan n'est en fait qu'une équivalence, le même endroit, l'Alpha et l'Omega de ce cycle refermé sur lui-même dans l'espace comme dans le temps, sur scène. Nous voyons ceci dans la mise en scène du Rabinal Achi. Le Baron des Quichés: «después solicita la última gracia: ir a despedirse de sus montañas durante 13 veces 20 días, o sea 260 días, lo que constituía un año del calendario religioso. El protagonista hace mutis por un momento con lo que se simboliza el largo viaje realizado y vuelve danzando». ${ }^{134}$

On pourrait aussi soutenir que le voyage de Quetzalcóatl vers Tlilan Tlapalan, vers la mer et le ciel, l'autre monde, constitue le modèle de la mort en général et non seulement les funérailles royales. Quetzalcóatl montre aux hommes le chemin et leur promet le retour sur terre, la résurrection. Sa

I3I. Cristóbal del Castillo, Historia de la venida de los mexicanos y de otros pueblos e historia de la Conquista, Cien de México (Ciudad de Mexico: Secretaría de Educación Pública, 200I), 93, note 24 de Federico Navarrete Linares.

132. Miguel León Portilla, «Teatro náhuatl prehispánico», in La Palabra y el Hombre. Revista de la Universidad Veracruzana (1959): 31.

133. Sahagún, Códice Florentino, III: IV: IIv; Historia General, 2000: $31 \mathrm{I}$.

134. Hyalmar Blixen, «El Rabinal Achi y el teatro danzado de los mayas», disponible en http:// letras-uruguay.espaciolatino.com/blixen_hyalmar/rabinal_achi_y_el_teatro_danzado.htm 
légende sert donc aussi et peut-être surtout à consoler les mortels de leur mort inévitable, leur promettre un retour à la vie en Quetzalcóatl. Ecoutons Tezozómoc raconter l'angoisse de Moctezuma qui devant l'arrivée des espagnols préfère aller se cacher chez Huemac, dans la grotte de Chapultepec, c'est à dire se suicider, ou se faire immoler dans cette grotte. Pour l'en dissuader, Tzoncoz lui parle:

Mirad, señor, lo que oy se trata del Çe teuchtli que lleuo consigo Quetzalcóatll. ¿No fueron a morir a Tlapalam por la Mar del Çielo arriba? Y sus prençipales de ellos llamados Matlacxochitl y Oçomatli y Timal, que fueron estos los mayores nigromanticos del mundo en Tula, y al cabo ¿̨no binieron a morir? Que los llevo su rrey y señor Quetzalcóatll, no estan agora en el mundo. Agora, seńor, ¿que te fatigas, que as? Torna en si agora mas alegria que nunca tubiste en la bida, agora goza tu noble juventud, floresçe, y ese animo agora mayor que nunca lo tubiste en la bida, agora mucho rregozixo, fiestas, alegrias en jardines, huertas.

Moctezuma lui répond: Abeisme hecho mucho plazer y me abeis dado mucho consuelo. ¿Quien me consolara como agora me abeis consolado? ${ }^{135}$

\section{Intronisation royale}

Nous pouvons encore considérer que si le modèle Quetzalcóatl est celui des funérailles royales ou de la bonne mort en général, il est aussi celui de l'intronisation: «Ya de oy, señor, quedais en el trono, silla, que primero pusieron $\mathrm{Ce}$ Acatl y Nacxitl Quetzalcóatll». ${ }^{136}$

Heredado has el estado real de muy ricas y hermosas plumas y el aposento de piedras preciosas que dexó el dios Quetzalcóatll y el gran Topiltzin. ${ }^{137}$

Asi mesmo tenian por preeminencia los dos sumos sacerdotes dichos de confirmer en los estados á todos los gouernadores y Reyes desta Nueua Espańa desta manera que los tales Reyes ó caçiques en heredando el Reyno ó señorio venian á esta ciudad á reconoscer obedençia al ydolo della queçalcoatl. A qual ofrescian

I35. Tezozómoc, Crónica mexicana, CVII, 464.

136. Tezozómoc, Crónica mexicana, LVIII, 200I:249.

137. Durán, Historia de las Indias de Nueva España, XXXIX: 359. 
plumas Ricas, mantas, oro, y piedras presciosas y otras cosas de valor y auiendo ofrescido los metian en una casilla que para este efecto estaua dedicada en la qual los dos sumos sacerdotes los seńalauan horandandoles las orejas las narices ó el labio inferior segun el seńorio que tenian. ${ }^{138}$

Eloise Quiñones Keber a vu les relations entre les rites d'intronisations des rois et les mortifications de Topiltzin Quetzalcóatl à Tula. Elle écrit: «The types of self-sacrifice and penance associated with Topiltzin Quetzalcóatll in the text were performed by rulers as part of dynastic ceremonies». ${ }^{139}$

Emanuela Mónaco voit aussi dans la saga de Quetzalcóatl le modèle de la transmission dynastique: «Topiltzin Quetzalcóatl representa y funda la realeza elemental, de tipo dinástico». ${ }^{140}$ Tout d'abord, l'avènement d'un nouveau roi succède en général à la mort du précédent, et dans le cas de conquêtes, le nouveau roi peut être tout simplement le conquérant qui vient d'achever la dynastie locale pour prendre la place du mort. Mort parfois pour avoir été sacrifié par le vainqueur qui lui succède. Et puis, le rituel d'investiture est, comme la plupart des rites d'initiation, essentiellement une mort et renaissance. Nous pouvons donc supposer que la mort et la renaissance du roi était accompagnée de celles de Quetzalcóatl, le modèle même de la royauté, qui mourrait avec le roi et renaissait avec son successeur, en quelque sorte une version mexicaine $\mathrm{du}$ Le roi est mort, vive le roi. L'acteur Quetzalcóatl pouvait bien jouer cette mort et renaissance glorieuses du roi lors des cérémonies de funérailles et d'investitures royales, en parallèle, et représenter théâtralement l'immortalité de la fonction royale. Léon Portilla le confirme:

Además de los declamadores, hicieron su aparición los grupos de actores que representaban plásticamente las leyendas y los mitos. En el repertorio de textos recogidos por Sahagún, así como en la colección de cantares mexicanos y en otros documentos más, hallamos no pocos himnos y poemas que denotan claramente la presencia de diversos personajes que dialogan entre sí, ofreciendo los momentos culminantes de los antiguos mitos y leyendas nahuas. Como es obvio, no siempre se afirma expresamente que dichos himnos y poemas podían ser representados. Sin embargo, su lectura nos muestra que parecen concebidos precisamente para ser

138. Gabriel Rojas, «Relacion de Cholula», Revista Mexicana de Estudios Históricos I (1927), I6I.

139. Quiñones Keber, Topiltzin Quetzalcóatl in Text and Images, 64.

I40. Mónaco, «Quetzalcóatl de Tollan», I40. 
puestos en escena. Aquí vamos a transcribir tan sólo uno de esos poemas pertenecientes a la colección de cantares mexicanos. En él se recuerda el gran mito de la huida de Quetzalcóatll que abandonó Tula y marchó hacia el oriente, hacia Tlilan Tlapalan, «el lugar del color negro y rojo», la tierra de la sabiduría. Oigamos el texto y procuremos imaginar la acción que lo acompañaba. Es tal vez un cantor quien da principio al poema que recuerda y describe la salida de Quetzalcóat1l, nuestro príncipe, Nacxitl Topiltzin, al abandonar a Tula. ${ }^{14}$

En Tula una casa de tablones,

Sólo quedan columnas cual serpientes,

La dejo abandonada Nacxitl,

Nuestro príncipe [Topiltzin. ${ }^{142}$ ]

Con música de caracoles

Son llorados nuestros principes,

Van a perderse alla en Tlapallan. ${ }^{43}$

Ainsi pleure et se lamente Matlacxochitl, le successeur de Quetzalcóatll sur le trône de Tollan.

\section{Que penser?}

Les sources prétendument historiques concernant les rois de Tollan ne sont que désordres et contradictions. Davies; ${ }^{144}$ Prem $^{145}$ et Graulich ${ }^{146}$ analysent logiquement toute la documentation, pour essayer de remettre de l'ordre dans la succession dynastique de Tollan, mais évidemment sans aucun succès. Le résultat de leurs investigations montre que l'on ne peut faire aucune confiance aux sources soi-disant historiques. Tout cela ne s'explique que par la mythologie et la légende. Mais il semble pourtant certain qu'un ou plutôt plusieurs Quetzalcóatl aient vécu sur terre en chair et en os, historiquement. Ne les oublions

I4I. León Portilla, Teatro náhuatl prehispánico, 30, citant Cantares Mexicanos.

I42. Topiltzin dans l'original nahuatl, traduit ici par nuestro principe.

I43. Cantares Mexicanos, trad. y n. de Miguel Leon Portilla, 3 vols. (Ciudad de México: Universidad Nacional Autónoma de México, 20II), II: 35I.

I44. Nigel Davis, The Toltecs Until the Fall of Tula (Norman: University of Oklahoma Press, 1977).

I45. Hanns Prem, "Los dos reyes de Tollan y Colhuacan", Estudios de Cultura Náhuatl, nr. 30 (1999): 23-70.

146. Graulich, Los reyes de Tollan. 
pas, célébrons leur mémoire, ce sont eux tous qui ont créé le Quetzalcóatl abstrait et divin. Graulich fait à ce propos une remarque précieuse:

L'habitude aztèque de désigner un personnage par le nom du dieu qu'il personnifie, ou même, qu'il porte, fait mieux comprendre comment, dans le récit du meurtre de Copil, celui-ci est tué par un prêtre, soit par un prêtre portant Huitzilopochtli, ou par Huitzilopochtli lui-même. On voit mieux aussi par quel biais on est arrivé, dans les récits de pérégrinations plus ancienne, à ne plus mettre en scène que des dieux. ${ }^{147}$

Notons qu'il contredit ici complétement l'expression de son mépris pour l'explication évhémériste exprimé par ailleurs. ${ }^{148}$ D’ailleurs Cristobal del Castillo décrit exactement cette transformation réelle d'un héros en dieu. Le chef des aztèques se transforme en image du dieu Huitzilopochtli puis devient luimême Huitzilopochtli:

Y tambien con esto te favorecemos, pues tu seras Tetzauhteotl, en efecto seras su imagen, por lo que te llamaran Huitzilopochtli Tetzauhteotl. Ya habeis escuchado lo que me fue ordenado. Y eso tambien os lo ordeno, porque en verdad ya soy su imagen, ya me hice nuestro dios Tetzauhteotl. ${ }^{149}$

Nous pouvons encore remarquer qu'à considérer le nombre impressionnant d'explications, d'interprétations, de commentaires, et de méditations qu'a suscité le personnage de Quetzalcóatl, on voit bien qu'en ceci aussi il se présente comme une création littéraire, un chef d'œuvre de littérature mythologique et théâtrale, un archétype qui résonne à l'infini dans les âmes, au-delà des frontières culturelles locales, comme Hamlet ou CEdipe. La force et la profondeur des symboles qu'il éveille, et son ambigüité elle-même suscitent toutes les rêveries, féconde l'imagination. La richesse d'un texte littéraire ou mythologique, n'est-elle pas justement de se prêter à d'innombrables lectures et interprétations, et des plus variées? Par sa brièveté même, ses silences et ses contradictions internes, ce texte ouvre la porte à toutes les imaginations,

147. Graulich, Le sacrifice humain chez les Aztèques, 235.

I48. Voir plus bas son désaccord avec Cristóbal del Castillo, Graulich, Le sacrifice humain chez les Aztèques, 84.

I49. Cristóbal del Castillo, Historia de la venida de los mexicanos, VIII: 8. 
permet toutes les broderies, et la diversité des lectures et des commentaires. C'est ici la marque du chef d'œuvre! Comme dans la vie elle-même, nous ne sommes toujours que mal ou partiellement informés des causes et des effets, sans compter les pertes et destructions de documents, les torsions des sources, les manipulations idéologiques conscientes ou non, chacun se cache comme il peut. Les contingences et nécessités, la mécanique sociale et son protocole, les non-dits, les allusions, les mensonges, l'incompréhension, les malentendus, les timidités, les silences, les douleurs secrètes, les plaisirs cachés, et toutes les subjectivités produisent les plus étranges combinaisons. Comme dans la nouvelle d'Akugatawa, Dans le fourré, ${ }^{150}$ ou chacun raconte séparément sa version des faits, chacun des récits est vraisemblable et logique, ils sont pourtant tous complètement différents, et qui plus est, incompatibles. Avec les textes et commentaires concernant Quetzalcóatl, nous avons souvent l'impression de nous trouver dans la même situation. Pourtant, sur de nombreux points, les auteurs arrivent à tomber plus ou moins d'accord. De fait toutes les interprétations et solutions présentées sont acceptables, plus ou moins, et complémentaires. Et puis, dans les sciences humaines, les niveaux de lecture, les points de vue, les changements d'angles, de cultures ou d'époques font sans cesse apparaître de nouveaux aspects pas toujours incompatibles avec ceux déjà connus par d'autres analyses. En adoptant ce nouvel éclairage d'un Quetzalcóatl acteur, de très nombreuses contradictions disparaissent. Car il faut bien l'avouer, ce ne sont pas les contradictions internes qui manquent ici. Une courte revue des problèmes posés par la figure de Quetzalcóatl, figure emblématique pour la compréhension des cultures de Mésoamérique montre à quel point ce personnage reste énigmatique, insaisissable et comme il laisse le lecteur perplexe. La documentation existante et les études sur Quetzalcóatl révèle une grande variété de points de vues, nous trouvons:

- Un Quetzalcóatl Guerrier, un autre pacifiste. Ils ne sont pas du même âge, le premier est un jeune conquérant, le deuxième, par force sans doute vient de faire son adieu aux armes.

- Un ermite opposé à toute violence ou un dieu vengeur et sanguinaire.

- Un prêtre, le grand prêtre par excellence ou tout au contraire la victime impuissante aux mains des prêtres, un pantin manipulé dont on se moque.

- Parfois dieu et d'autres fois un homme tout simplement. Un simple et

150. Ryubosuke Akugatawa, Dans le fourré, Rashomon et autres contes (Paris: Gallimard, 1965). 
pauvre mortel malade, d'une laideur repoussante, ou le représentant de l'humanité toute entière, le modèle canonique de la beauté humaine, son symbole, son rédempteur.

- Un grand roi, le modèle des rois, le roi des rois ou un prisonnier de guerre, un guerrier déchu, vaincu. Un roi de carnaval, de pacotille, par dérision.

- Le modèle théorique des funérailles royales ou bien la représentation différée de la mort du roi.

- La représentation théâtrale de l'intronisation royale et son modèle.

J'espère pouvoir montrer et convaincre que tous ces aspects peuvent se retrouver et justifier dans un même personnage: Quetzalcóatl acteur du mystère religieux préhispanique. Il faudrait pouvoir lire la vie de Quetzalcóatl comme celle d'une composition littéraire faite d'un collage à partir de fragments historiques, mythiques, légendaires et rituels, de représentations commentées, un ensemble inséparable d'éléments ayant servis à sa composition. Et surtout comme la description de la représentation de la vie et de la mort du dieu sur terre, dans la peau de son représentant.

L'auteur anonyme des Annales de Cuaubtitlan, comme Sahagún, Durán, Juan Cano, l'Hystoire du Mechique, la Leyenda de los soles, et la Historia de los mexicanos por sus pinturas, entre autres ${ }^{\mathrm{ISI}}$ nous rapportent l'histoire du roi de Tollan, Topiltzin Quetzalcóatl, ou plutôt, et ceci est déjà un signe, ils ne nous disent presque rien de sa vie, mais seulement des conditions de sa fin: 2-Acatl. Es relacion de Tezcoco que en este año murio Quetzalcóatl Topiltzin de Tollan en Colhuacan, ${ }^{52}$ 3-Tecpatl, 4-Calli, 5-Tochtli, 6-Acatl, 7-Tecpatl, 8-Calli, 9-Tochtli, Io-Acatl, II-Tecpatl, I2-Calli, I3-Tochtli, I-Acatl, en este año murió Quetzalcóatl. ${ }^{53}$

Le texte des Annales rapporte laconiquement la naissance de Topiltzin Quetzalcóatl et avec plus de détails la fin du grand roi de Tollan. Toute la description de la naissance, de la vie et de la mort du roi occupe quatre pages manuscrites serrées qui couvrent la totalité de l'année $I$-Acatl, ${ }^{154}$ importante

I5I. Voir la revue savante que, Nicholson, Topiltzin Quetzalcóatl, the Once and Future, donne des sources.

152. Annales, 35 .

153. Annales 39.

I54. Remarquons, autre contradiction du texte que l'on annonce sa mort dans l'année 2-Acatl pour affirmer plus loin qu'il mourut l'année I-Acatl. Mais on précise que la première date est 
entre toutes. Puis, de nouveau, comme avant, la litanie des années qui passent file vers l'avenir: 2-Tecpatl, 3-Calli, 4-Tochtli, 5-Acatl, 6-Tecpatl, 7-Calli, 8-Tochtli, 9-Acatl, ıo-Tecpatl, II-Calli, -I2-Tochtli, I3-Acatl, 2-Calli, 3-Tochtl, ${ }^{\text {Iss }}$ Comme si le seul évènement important de cette période historique ancienne avait été la mort du grand roi Topiltzin dans l'année $I$-Acatl, l'année même de sa naissance. Ce récit se présente comme une histoire chronologique. La vie de Topiltzin fait suite à celle de Coyotzin et lorsqu'elle s'achève, le règne de son successeur Matlacxochitl commence. On y relève pourtant plusieurs singularités qui invitent à y regarder de plus près. Tout d'abord, non seulement le roi porte un nom divin, mais les ennemis et alliés du roi eux-mêmes ne sont pas de simple humains: Tezcatlipoca le démon au miroir, Toltecatl le dieu du Pulque, ${ }^{156}$ Ihuimecatl un autre dieu des ivresses et Coyotlinahual le plumassier divin, sont des êtres mythiques, des dieux. Il est bien vrai aussi que tous les Pierre ou les Arthur ne sont pas le disciple de Jésus ou le Roi de la Table Ronde, mais que penser de tout cela? -Si nous lisons ce texte comme une chronique historique du royaume de Colhuacan ou de Tollan, comment interpréter les noms des acteurs divins de l'opéra des dieux? Et si nous le lisons comme un récit mythique, comment expliquer qu'il soit inséré dans une suite chronologique strictement datée en temps réel? Inscrit dans une lignée de succession dynastique entre Coyotzin ou Ihuitimal et Matlacxochitl ou Huemac avec des mentions d'autres souverains et personnages contemporains jusqu'aux époques modernes et la venue des espagnols, fait on ne peut plus historique. S'agit-il d'une chronique historique ou d'un récit mythique? Que ces récits soient souvent légendaires, mythiques et divinatoires semble évident ou du moins probable, mais même alors, cela ne devrait pas empêcher la possibilité d'un ancrage historique pour les parties qui se présentent comme des allégories astronomiques et peuvent avoir été jouées à l'opéra des dieux pour un public bien terrestre à l'occasion des grandes cérémonies, et donc à un moment précis de la chronologie humaine. Le fait qu'une histoire généalogique commence par des origines légendaires et même quasi divines est affaire courante sur tous les continents, mais cela n'implique pas qu'aux générations suivantes, elle ne puisse reposer sur des archives parfaitement documentées. Si en Europe nous

donnée selon la tradition de Texcoco, sans nous informer du système de la deuxième date, mais la plupart des sources confirment bien la date I-Acatl pour sa naissance et sa mort.

155. Annales, 53 .

I56. Sahagún, Códice Florentino, I: XXII: 23v, I: Apéndice: 4or; Sahagún, Historia General, III, I24. 
croyons savoir bien définir les limites entre mythe, légende et histoire, c'est peut être que nous sommes encore, grâce à Dieu, très profondément enracinés dans nos propres convictions culturelles et idéologiques. ${ }^{157}$ La distance aidant, il nous est moins pénible de voir à quel point histoire et mythologie peuvent parfois s'entrelacer en Méso-Amérique. Là, nous le voyons, nous sommes en pleine histoire mythique. Chacun adapte le modèle à sa propre histoire ou plutôt fait entrer l'histoire dans les structures mythiques et idéologiques préétablies. Et même en Europe où l'on prétend savoir bien séparer histoire, religion, mythe et légende et ou le mythe, la légende et la fable relèvent de l'affabulation, de la littérature, on pourrait pourtant bien souvent formuler ainsi leurs rapports: La mythologie est l'histoire des vaincus et l'histoire, la mythologie des vainqueurs. Je ne ferais pas pour ma part une différence bien nette entre ces deux types de récits. En Mésoamérique surtout, ou toutes les cultures sont des variantes d'un même ensemble fondamental, l'intégration et la cohérence interne sont d'une grande force, et la symbiose entre vainqueurs et vaincus successifs est si complète qu'il devient presque impossible de séparer l'histoire du Mythe. Les ennemis sont des ennemis intimes respectant les mêmes règles du jeu. Les vaincus sont littéralement mangés et digérés et deviennent partie intégrante des vainqueurs, inséparables. Les vainqueurs nouveaux venus se font assimiler par l'ancienne société millénaire et ses coutumes et structures mentales les plus profondes. Les traditions méso-américaines semblent avoir systématiquement essayé de calquer l'histoire sur la mythologie et la mythologie sur l'histoire. Système idéologique dans lequel le jeu politique est légitimé par son insertion dans l'idéologie religieuse. La mythologie s'y trouve inscrite dans un ordre astronomico-cosmique strictement calculé servant de trame et de modèle à sa représentation théâtrale: un rituel fastueux de l'opéra céleste, dans lequel les hommes endossent les rôles des dieux.

Sabian cuando viene apareciendo, en que signos y cada cuando resplandece, les dispara sus rayos y les muestra enojo. Si cae en I-Cipactli (espadarte), flecha a los viejos y viejas, a todos igualmente. Si cae en I-Ocelotl (tigre), si en I-Macatl (venado), si en I-Xochitl (flor), flecha a los muchachitos. Si en I-Acatl (Caña), flecha a los grandes señores, etcetera. ${ }^{158}$

I57. N'en déplaise aux déconstructeurs de salon.

158. Annales, 5I. 
Rituel et politique, mythe et histoire sont, dans l'ancien Mexique, étroitement entrelacés. Les sociétés mésoaméricaines sont éminemment conventionnelles et théâtrales. Si nous voulons mieux entendre le contenu des archives et sources anciennes, il est nécessaire de garder ces considérations à l'esprit et lire la masse des informations comme les variantes ou les différents niveaux d'interprétation d'un seul ensemble cohérent. Cet effort suprême des civilisations méso-américaines pour créer une réalité physico-spirituelle unique et harmonieuse s'est fait au prix, bien sûr, de quelques distorsions et d'abus symboliques. Il faut aussi compter sur quelques glissements, erreurs et trahisons dans les copies, les résumés et les traductions qui nous sont parvenus. Les sources méso-américaines se tiennent toutes entre elles dans une inextricable composition faite à partir des ruines et fragments de milliers d'années d'histoire et selon la technique du collage et du palimpseste. Tous les monuments sont construits à partir des matériaux du passé. Tel fragment ancien a été détourné au profit d'une nouvelle écriture de l'histoire, après la destruction des livres anciens comme cela est attesté chez les Aztèques: "y se sabia por las pinturas que se quemaron en tiempo del señor de México que se dezia Itzcoatl, en cuyo tiempo los señores y los principales que avia entonces acordaron y mandaron que se quemasen todas, porque no viniesen a manos del vulgo, y viniesen en menosprecio». ${ }^{59}$

Revenons à la diversité des hypothèses explicatives à propos de Quetzalcóatl. Il me semble donc qu'il ne serait pas impossible de concilier les tenants des deux points de vue principaux qui s'opposent depuis si longtemps, l'historique et le mythologique. Le seul lieu où l'on rencontre la fusion du temps des dieux et de celui des hommes, l'histoire et l'éternité, c'est celui de l'incarnation et l'autel du sacrifice. On peut donc dès lors lire ces récits comme une liturgie, la description du rituel de préparation de la victime sacrificielle et son immolation en l'honneur de l'étoile du matin pour le renouveau des temps. Le modèle premier est sans doute religieux, mythologique, ce qui n'empêche pas que cet opéra divin ait pu être représenté sur terre et que l'on puisse donc le traiter historiquement. Exactement comme Hamlet est un personnage de faible consistance historique, mais qu'il a servi de modèle à plusieurs œuvres littéraires et qu'il a été très souvent joué, par des acteurs réels, dont on peut connaître l'identité, à différentes dates, dans de nombreuses salles de pays différents, nous avons les critiques dans la presse et les recettes des représentations 
dans les livres de comptes. Bien que traduit dans toutes les langues, c'était à chaque fois le même Hamlet, et chaque fois différent. Beaucoup plus près culturellement et géographiquement de la tradition de Cuauhtitlan, nous disposons du texte maya-Quiché du Rabinal Achi et de ses représentations toujours vivantes. Quetzalcóatl fut un homme-dieu joué sur scène en différentes époques, dans différentes cultures, et pendant plus d'un millénaire, depuis les débuts de Teotihuacan jusqu'à la conquête espagnole. Ces représentations connurent sans doute de nombreuses variantes et variations, une certaine évolution historique. De plus, les sources multiples n'ont pas toutes rapporté le même aspect du mythe et des rites, des croyances. Tout cela pour finir a été rassemblé en une sorte d'amalgame. Il faut ajouter aussi que les chroniqueurs du XVI siècle se sont fait des idées différentes des témoignages qu'ils recueillaient, et n'ont noté que les aspects qui leurs semblaient personnellement les plus remarquables. Ces témoignages eux-mêmes provenaient d'informateurs issus de diverses cultures, décrivant des représentations ou traditions différentes, et enfin, la mémoire de chacun est sélective. Pour ces raisons aussi les sources different. Mais il me semble que nous pouvons maintenant mieux comprendre et décrire le complexe culturel centré sur Quetzalcóatl, l'acteur exemplaire de la vie et de la mort du dieu fait homme ou de l'homme-dieu. Dès l'heure, je tiens aussi à mentionner qu'il me semble que si les parties existantes des Annales présentent toutes les marques de l'authenticité, je suis bien d'accord pour accepter qu'il manque une partie des textes d'origine. Qu'une partie des sources compilées par le rédacteur ultime a été perdue accidentellement, ou plus certainement volontairement omise, abrégées pour ne pas fatiguer le lecteur nous disent plusieurs chroniqueurs: "por excusar prolijidad no se ponen aquí». ${ }^{160}$ Le chercheur moderne regrette infiniment ces coupures. Mais il y a aussi des coupures dictées par la pudeur ou la prudence. Dans ce cas, ce serait le signe d'une adaptation pour l'interlocuteur chrétien, une sorte de mensonge par omission, une dissimulation, et en ceci seulement se situerait une certaine distorsion chrétienne du texte, mais non pas dans ce qui est rapporté. Par exemple, même en se limitant strictement au texte des Annales, on soupçonne que le héros meurt deux fois, bien que nous ne trouvions aucune trace de la première mort qui se situe selon moi entre la nuit d'ivresse et de noces et le chemin de l'exil vers Tlilan Tlapalan. Tout comme Patrick Johansson, Michel Graulich avait déjà remarqué que le voyage à Tlilan Tlapalan pouvait 
s'entendre comme un voyage dans le monde des morts, dans l'autre monde, un voyage post-mortem:

Luego hay el viaje propiamente dicho. Sabemos a ciencia cierta que se trata de la transposición de un viaje infernal en un trayecto de oeste (el paraíso de Tollan está necesariamente ubicado al oeste) a este, o sea el curso del sol después de ponerse. En efecto, no sólo se dice francamente que Quetzalcóatl edifica las casas del Lugar de los muertos (Mictlancalco) - lo que es comprensible al comienzo de una era - sino que además, varias de sus jornadas corresponden a igual número de estaciones en el inframundo. Desde la partida hay como una preparación a la muerte. El dios se ve viejo y llora. Según los Annales, se encierra cuatro días en una caja de piedra: en otras palabras, es como si estuviera muerto y enterrado (el dios supremo pone al rey muerto en una caja). Luego cruza el río Tepanoayan, es decir el infernal Apanoayan que cierra el paso al país de los difuntos. ${ }^{16 r}$

López Austin avait à ce propos bien justement remarqué lui aussi, que le séjour de quatre jours dans la caisse de pierre avant de partir pour Tlilan Tlapalan devrait marquer la mort de Quetzalcóatl: «Tal vez este detalle permita suponer que la marcha hacia Tlapallan se hace, simbolicamente, cuando Quetzalcóatll ha muerto». ${ }^{162} \mathrm{Il}$ semble donc bien manquer quelque chose entre ces deux épisodes de la nuit d'ivresse et du départ vers Tlilan Tlapalan. Un manque résultant probablement d'un silence sur l'acte même du sacrifice sanglant, de la mise à mort, un oubli pudique en présence du lecteur chrétien, à moins qu'il n'affirme par son silence même que la mort n'est rien, rien qu'un changement de monde, un changement de costume, un départ en voyage, un passage de frontière. Ce silence sur l'instant de la mort pourrait aussi provenir d'une pudeur littéraire déjà de bon ton avant la conquête, en quelque sorte la bienséance de notre théâtre classique: Ce qu'on ne doit point voir. ${ }^{163}$ Saburo Sugiyama note aussi très justement qu’à Teotihuacan:

Las escenas pictográficas que se habían interpretado como rituales mitológicos, en realidad representan hechos reales, y aunque no se han identificado escenas de

I6I. Graulich, Quetzalcóatl y el espejismo de Tollan, I8I-I82.

162. Lopez Austin, Hombre-Dios. Religión y politica en el mundo náhuatl, I40, faisant référence à Cristóbal del Castillo, Historia de la venida de los mexicanos, cap. 5.6, I2I; Annales, 47 et 50.

I63. Boileau, l'Art poétique, édition de Guy Riegert (Paris: Larousse, I972 [primera edición, I674]) chant III, vv.5I-54. 
sacrificio humano explícitas o realistas, existe una gran cantidad de imágenes de cuchillos, de corazones, de gotas de sangre y otros símbolos relacionados con las representaciones de sacerdotes en acción ritual o con los guerreros que supuestamente capturaban cautivos para los rituales. ${ }^{164}$

Graulich avait remarqué déjà qu’à Teotihuacan, les artistes: «Evitan escenas explícitas: tenemos por ejemplo alusiones al sacrificio humano pero ninguna representación del acto». ${ }^{165}$ Sylvie Peperstraete le souligne à son tour: «Les artistes précolombiens ont préféré montrer d'autres moments du rite, précédant ou suivant l'exécution de la victime, voire parfois tout simplement procéder par allusions». ${ }^{166}$

Nous trouvons la même bienséance littéraire et théâtrale dans l'évocation pudique de la nuit d'ivresse de Quetzalcóatl et de sa sœur Quetzalpetlatl: «Después que se embriagaron, ya no dijeron: 'Pero si nosotros somos ermitanos!' Ya no bajaron a la acequia; ya no fueron a ponerse espinas». On se contente de cerner ce qui s'est fait par ce que l'on n'a pas fait. Ces ultimes délices terrestres sont tout le contraire des macérations. Il faudra essayer de combler ces épisodes muets à partir de versions parallèles et des gloses. Le texte des Annales peut être lu comme la description de la préparation de la victime sacrificielle pour le culte du renouveau de Venus Etoile du Matin et par extention pour tout renouveau, toutes inaugurations. Cette relation est largement attestée par de nombreuses sources, et pour n'en citer qu'une, celle de Motolinia qui après s'être longuement étendu sur le culte de la planète Vénus, ajoute que si cette planète était tant vénérée, c'est qu'ils croyaient que leur dieu principal, Topiltzin, nommé aussi Quetzalcóatl, lorsqu'il mourut et quitta ce monde, fut transformé en cette étoile resplendissante:

Despues del sol, a esta estrella adorauan e hazian mas sacrifiçios que a otra criatura ninguna, çelestial ni terrenal. Despues que se perdia en occidente, los astrologos

164. Saburo Sugiyama, «Sacrificios humanos dedicados a los monumentos principales de Teotihuacán", in Guilhem Olivier y Leonardo López Luján, coords., El sacrificio humano en la tradición mesoamericana (Ciudad de México: Universidad Nacional Autónoma de México/ Instituto Nacional de Antropología e Historia, 20Io), 82-83.

165. Michel Graulich a rajouté ce fragment dans la version dactylographiée, publiée online et non datée, page 8 de son texte de 1988, Quetzalcóatl y el espejismo de Tollan, Io.

I66. Sylvie Peperstraete, «Le sacrifice humain au Mexique central préhispanique. Mise en scène et en images d'un rite spectaculaire», in Image et spectacle, coord. Thierry Lenain, Degrés I52 (Bruselas: Helbo, 20I2), I-IO, h 6. 
sabian el dia que primero auia de volver a apareçer el oriente. Y para aquel primer dia aparejauan gran fiesta y sacrifiçios... La causa y rrazon porque contauan los dias por esta estrella y le hazian rreuerençia y sacrifiçio era porque estos naturales engańados pensauan e creian que vn de los prinçipales dioses llamado Topilçin y por otro nombre Quetzalcouatl, quando murio y deste mundo partio, se torno en aquella rresplandeçiente estrella. ${ }^{167}$

Ces quelques pages des Annales constitueraient donc la description fragmentaire et incomplète de la préparation en coulisses et de la représentation théâtrale d'un mystère religieux donné en spectacle. López Austin rappelle d'ailleurs une remarque de Jorge Acosta: «Para Jorge R. Acosta es un misterio que no haya testimonio alguno de la rivalidad entre los adoratores de Quetzalcóatll y los de Tezcatlipoca... después de esta brilliantísima observación». ${ }^{168}$ Nous comprenons beaucoup mieux cette absence d'animosité sectaire, si les spectateurs d'une seule et même religion assistaient à ces représentations de deux acteurs adversaires sur scène mais appartenant à la même mythologie, acteurs d'un même drame, et surtout de la même troupe, formés dans la même école. Comme si les représentations de la Semaine Sainte à Iztapalapa mettant en scène Jésus et Pilate témoignait de la lutte des fidèles de deux sectes opposées. D’ailleurs, le sacrifice et le repas de communion servent principalement à pacifier et unir tous les membres d'une société en crise, sous tension, à rétablir la paix sociale entre ennemis intimes. Le capteur et son captifs dansaient ensemble avant le sacrifice: «Cada uno de los que yvan en el areyto assi adereçados yva pareado con su captivo: yvan ambos dançando a la par». ${ }^{169}$ Et tous ensembles même après le sacrifice:

Acabado de acuchillar y matar a los captivos, luego todos los que estavan presentes, sacerdotes y principales y los señores de los esclavos, començavan a dançar en su areyto, en rededor de la piedra donde avian muerto a los captivos. Y los señores de los captivos en el areyto, dançando y cantando, llevavan las cabeças de los captivos asidas de los cabellos. ${ }^{170}$

167. Toribio de Benavente Motolinía, Memoriales, XVI: 4, 1996: I83.

168. López Austin, Hombre-Dios. Religión y politica en el mundo nábuatl, 36, citant Jorge Acosta, Historia natural y moral de las Indias, I07-I08.

169. Sahagún, Códice Florentino, II: XXIX: 63r; Historia general, 225.

170. Sahagún, Códice Florentino, II: XXI: 23r; Historia general, 184. 
Mon optique qui consiste à traiter les sources concernant Quetzalcóatl comme descriptions de la représentation théâtrale du mystère divin répond à bien d'autres énigmes et interrogations. Michel Graulich remarquait très justement que:

Un examen plus approfondi du mythe de Teotihuacan fait apparaître des obscurités et d'apparentes incohérences remarquables. D'abord, que font les dieux sur terre, dans les ténèbres? Pourquoi sont-ils pesants, matériels, et pourquoi l'un d'entre eux est-il bubonneux, comme un homme atteint d'un châtiment divin pour avoir péché? Pourquoi et comment sont-ils devenus mortels? Pourquoi doivent-ils mourir dans un feu qui détruit le corps ou sous le couteau sacrificiel? ${ }^{\text {r7 }}$

L'auteur commente ici le sacrifice de Nanahuatl, une des incarnations de Quetzalcóatl au moment de la création du cinquième soleil à Teotihuacan, c'està-dire, là où l'on crée les dieux. On y crée les dieux, justement, et non pas les hommes! Serait-il exagéré de lire dans les noms mêmes des dieux Tonacatecuhtli y Tonacacíhuatl, «Señor y Señora de nuestra Carne» qu'ils sont vraiment les produits de notre chair. Ils sont les dieux primordiaux, la partie palpable du principe de dualité qui préside à la création: Ometecuhtli y Omecíhuatl, Señor Dos y Señora Dos. Teotihuacan est le lieu où les hommes se font dieux, ou sont créés les dieux, où les hommes créent les dieux, leur prêtent corps: «Y se llamo Teotioacan el pueblo de teutl, que es dios, porque los señores que alli se enterravan despues de muertos, los canonizavan por dioses». ${ }^{172}$ Teotihuacan est le lieu où les hommes créent les dieux. Mendieta rapporte que: «Algunos de los indios daban a entender que sus dioses eran o habían sido primero puros hombres». ${ }^{173}$

Pour la création du soleil et de la lune à Teotihuacan, le texte de Sahagun ne laisse subsister aucun doute, il s'agit d'une représentation théâtrale rituelle: "Ya es el levantamiento, cuando aún es de noche, para que cumplan su oficio, se convierteron en dioses. Y cuando ya se cerca la medianoche, entonces les ponen a cuestas su carga, los atavian, los adornan». ${ }^{174}$

I7I. Graulich, Le sacrifice humain chez les Aztèques, 6I. à propos du texte de la Leyenda De los Soles.

172. Sahagún, Códice Florentino, X: XXIX: párrafo I4: I43 r; Sahagún, Historia general, 974.

173. Mendieta, Historia eclesiástica indiana, I9I.

174. Sahagún, Códice Matritense, in Miguel Leon Portilla, editor de Anónimo, Cantos y crónicas del México antiguo, 58-6o. 
Muñoz Camargo l'explique clairement lorsqu'il rapporte les questions des Tlaxcaltèques aux Espagnols pour savoir s'ils sont ou non des dieux et que ceux-ci leur répondent être les enfants du dieu unique venus les libérer de leur idolâtrie:

Declaraos ya con nosotros y no querais que con torpe engańo caigamos en otros mayores errores; porque si ansi es como decis, que no hay mas de un solo Dios y que todos los demas son compuestos y fabricados por manos de hombres, que no hablan ni se mueven y que son estatuas sin sentido, ansi es verdad, te lo concedemos y confesamos; mas estos bultos y estatua a quienes servimos y adoramos son imagenes, figuras y modelos de los dioses que en la tierra fueron hombres y [que] por sus hechos heroicos y famosos subieron alla, donde viven en eterno descanso, como agora vosotros, que sois como dioses. ${ }^{75}$

Lorsque Graulich affirme qu'aucun des prêtres de l'ancien Mexique n'a laissé de trace, cela semble exagéré, il semble bien que cette déclaration et les pages qui suivent constituent vraiment une petite leçon de théologie préhispanique. Les hommes devenus dieux avaient pu être des héros historiques ou plus souvent des victimes mémorables ou l'accumulation des victimes des sacrifices successifs pour tel ou autre dieu, ou les trois ensembles pour donner force visuelle et pratique à des concepts. Cristobal del Castillo ne s'y était pas trompé lorsqu'il présente Huitzilopochtli comme un homme en chair et en os qui n'aurait été que le représentant du dieu Chose Effroyable ou Augure, Tetzauhteotl, en qui il se serait fondu à sa mort. ${ }^{176}$ Explication que Graulich trouve aberrante, ${ }^{177}$ je ne puis comprendre cette réaction de Graulich, tout au contraire je trouve cela parfaitement logique et compréhensible et d'une vérité absolue. Huitzilopochtli avait fini par se fondre dans la mort avec l'image idéale qu'on avait fait de lui, de son vivant et c'est ainsi qu'il était devenu immortel. Graulich ajoute: Mais laissons cet évhémérisme incongru, tout au contraire, il ne s'agit nullement d'évhémérisme, nous n'avons pas à faire à un héros historique, personnage exceptionnel entré dans la légende puis divinisé comme tel, mais d'un dieu abstrait, d'un concept préexistant s'incarnant dans une personne charnelle historique qui ne devient dieu qu'en endossant le rôle et n'avait nul besoin

175. Diego Muñoz Camargo, Historia de Tlaxcala (Madrid: Dastin, 2002), II: IV: 200.

176. Cristóbal del Castillo, Historia de la venida de los mexicanos, 93; II5; I23.

177. Graulich, Le sacrifice humain chez les Aztèques, 84. 
d'être exceptionnelle, elle pouvait être choisie parmi les hommes du commun, et c'est uniquement son rôle qui la rendait exceptionnelle, l'accumulation des sacrifices rendait cette divinité de plus en plus puissante. Nourrie de plus en plus de sang, elle grandissait et se gonflait et devenait de plus en plus exigeante. Les dieux se nourrissent de nos souffrances, de notre sang, de notre chair Tonacatecuhtli, Tonacacihuatl. Sahagún d'ailleurs affirmait, lui aussi, bien haut, la stricte humanité de Quetzalcóatl:

Llamaron dios a Quetzalcóatll, el qual fue hombre mortal y corruptible, que aunque tuvo alguna aparencia de virtud, segun ellos dixeron, pero fue gran nigromantico, amigo de los diablos: y por tanto amigo y muy familiar dellos, digno de gran confusion, y de eterno tormento: y no de que le festeiasen, como a dios, y le adorasen como a tal: herraron grandemente, vuestros antepasados, en la adoracion deste pobre hombre, mortal y corruptible: y dijeron del muchas y muy grandes mentiras, como en su historia, esta claro lo que dijeron vuestros antepasados: que Quetzalcóatll fue a Tlapallan, y que a de volver, y lo espereys es mentira que sabemos que murio. Su cuerpo esta hecho tierra. ${ }^{178}$

On reconnait ici chez Sahagún le travail de l'évangélisateur, de l'extirpateur d'idolâtrie, évidemment, mais il n'empêche qu'il n’aurait pu trahir ses chers indiens, ses informateurs, qui l'auraient certainement corrigé s'il s'était égaré, puisque c'est justement pour cela qu'il les avait réunis et qu'il leur faisait relire, commenter et amender ses écrits. Si aucun ne le fit c'est qu'aucun d'entre eux n'aurait pu nier l'humanité de Topiltzin, la victime du sacrifice. La critique ne concerne que la foi en sa divinisation post-mortem, et non pas son existence terrestre sous une forme purement humaine. Et d'ailleurs, seul le peuple pouvait avoir vraiment et aveuglément foi dans la divinité de Quetzalcóatl, les grands, les gens éduqués savaient bien qu'il n'avait été qu'un simple mortel. Lorsque Moctezuma Ihuilcamina va voir en compagnie de son frère Tlacaelel, les figures sculptées qu'ils se sont fait faire dans le rocher de Chapultepec, le roi dit à son frère: Hermano Tlacaelel, contentado me han estas figuras, las cuales serán memoria perpetua de nuestra grandeza, como tenemos memoria de Quetzalcóatl y de Topiltzin, de los cuales está escrito que, cuando se fueron, 'dejaron

178. Sahagún, Códice Florentino, I: Apéndice: 35 v-36 r; Historia general, I2I. 
esculpidas sus figuras en palos y en piedras', en quien adora la gente común, y sabemos que eran hombres, como nosotros. ${ }^{179}$

Pourquoi n'avons-nous pas écouté Moctezuma Ihuilcamina et Sahagún et Mendieta et Cristóbal del Castillo et d'autres? Pourquoi ne les avons-nous pas écoutés? Pourquoi ne les avons-nous pas crus sur parole? Les historiens ne veulent rien savoir sans textes et traces écrites, mais quand ils les ont, ils ne cessent de les critiquer, discuter et interpréter pour leur faire dire ce qui leur convient au mieux selon l'époque ou la mode. A ce propos, d'ailleurs, il me semble utile de mettre au clair pour le lecteur mon propre point de vue en ce qui concerne l'utilisation des sources et leur fiabilité. On trouve trop souvent à mon goût des déclarations mettant en garde contre des biais de toutes sortes. Ici ce sont les indiens qui ont adouci et embelli leur passé pour se présenter aux espagnols sous un jour plus conforme à l'idée que ceux-ci se faisaient de la civilisation et des bonnes mœurs. Là ce sont les espagnols qui avaient intérêt à noircir le portrait pour justifier la conquête et l'évangélisation, ou au contraire à l'édulcorer pour mettre le roi d'Espagne en appétit et gagner sa faveur. Ailleurs, des prêtres qui ne cherchaient qu'à protéger leurs ouailles et pour cette raison cachaient une partie de leurs vices et coutumes ou au contraire les accusaient de tous les vices pour glorifier leur travail d'évangélisation. Certains chroniqueurs ont déformé l'information par intérêt personnel ou parce que leurs propres limitations mentales les empêchaient de comprendre autrement. Ixtlilxochitl n'est pas fiable parce qu'il veut tout mettre à la sauce biblique. Il est évident qu'Ixtililxochitl a voulu accommoder les documents originaux qu'il avait sous la main avec la chronologie biblique, mais il n'en reste pas moins que les données et dates préhispaniques qu'il signale, bien que contradictoires, restent très dignes d'intérêt puisqu'elles proviennent certainement de documents originaux. Tezozómoc ne cherche quà faire l'apologie de ses ancêtres, grands nobles mexicas, il n'hésite pourtant pas à les montrer cruels et machiavéliques. Juan Cano est de mauvaise foi et n'a d'autre but que celui de justifier les droits de sa femme Isabelle et de sa descendance sur les terres de Moctezuma. La chronologie des Annales de Cuauhtitlan est délirante, etcetera. Enfin, chaque auteur et chaque époque tord le cou d'une autre manière à ce pauvre poulet de l'histoire. Un autre problème est celui des limites permises du champ d'investigation. A-t-on le droit dans un travail sur le Mexique préhispanique de rappeler l'évangile ou un rite 
amazonien? Il n'est tout simplement pas possible, sauf dans de rares cas, d'éliminer une information simplement parce qu'elle ressemble trop à quelque chose qui nous est familier en Europe. Devrait-on alors éliminer dans une étude sur les aztèques toutes les informations provenant des Mayas, des tarasques, voir des Tépanèques ou de Cholula ou Tlaxcala, même si nous y reconnaissons des traits communs frappants qui peuvent nous éclairer, et justement pour cela, en argumentant que cela est trop ressemblant pour être original, et qu'il s'agit donc d'un emprunt. Mais qui a emprunté à qui, dans ce cas? Il me semble que lorsque les peuples de Mésoamérique ont rapidement adopté un trait culturel chez les espagnols, les chrétiens, c'est parce qu'il y avait sa place toute prête structurellement. S'il avait été foncièrement inacceptable, il aurait été ignoré ou rejeté. Ces auteurs férus d'histoire n'acceptent rien qui ne soient fondé sur des documents écrits. Toute reconstruction théorique ou hypothèse sur des parties manquantes est regardée d'un très mauvais œil, surtout si elle ne s'accorde pas avec les convictions personnelles du lecteur. Il semblerait que ces attitudes critiques soient motivées par la conscience professionnelle et la probité intellectuelle, mais l'expérience montre qu'il y va plus souvent des intérêts de chacun, pire encore d'un tribut payé aux normes tacites du travail intellectuel et scientifique. Il faut se montrer critique pour faire partie de la bonne société. Et le pire de tout, se conformer sans même $s$ 'en apercevoir aux normes morales du moment. Si les indigènes condamnent la sodomie, c'est uniquement parce qu'elle ne semble pas être du goût des prêtres espagnols, pourtant, ni l'une ni l'autre de ces deux propositions ne me semble clairement justifiée et démontrée. Dans le travail d'investigations, il est certainement très utile que s'établisse une discussion, un échange d'idées, une confrontation des points de vue. Il est de mauvaise guerre de moquer ou d'éliminer complètement un auteur parce qu'il a présenté une ou deux idées irrecevables ou erronées. Son œuvre peut comporter par ailleurs de brillantes hypothèses et des intuitions lumineuses. Spinden s'est trompé de 260 ans dans sa corrélation, mais sa démonstration est brillante et d'une remarquable intelligence des calendriers et de l'astronomie préhispanique. Je ne puis accepter personnellement l'idée fixe et lassante à force d'être trop souvent répétée de Michel Graulich à propos de son soleil lunaire de l'après-midi comme reflet dans un miroir d'obsidienne à partir du méridien, qui n'apparait que dans une seule source et reste énigmatique, mais cela n'enlève rien à l'exceptionnelle perspicacité de bon nombre de ses analyses. Réinterpréter les sources, redresser ce que leurs auteurs ont déclaré sous divers prétextes et autres bonnes 
raisons pour mettre en doute tel ou autre point, est sans doute utile, mais en mettant tout en doute, tout le temps, ne prend-t-on pas alors le risque de déformer une deuxième fois au lieu de rectifier? D'autant que les auteurs modernes ne sont pas moins exempts que les anciens de ne voir midi qu'à leur porte, et de rectifier les sources dans le sens qui leur convient le mieux. Il faut évidemment connaître et retenir toutes ces opinions, critiques et réflexions, mais le mieux reste encore de garder tels quels les documents comme ils se présentent en essayant d'en comprendre les contradictions pour tenter de les résoudre. Seule la cohérence interne globale devrait nous guider, mais il restera toujours quelques incohérences. Essayons donc de nous diriger vers la solution la moins problématique possible. Tous les auteurs, sans exception, choisissent les documents en fonction de leurs propres convictions et hypothèses de départ. Le choix et l'ordonnancement est inévitable, on ne peut tout retenir en vrac. Chacun sélectionne et organise donc la masse documentaire selon son point de vue particulier, selon un éclairage qui lui est propre, ce qui est légitime. Je n'entrerai donc pas dans les interminables discussions méthodologiques ou luttes idéologiques pour justifier s'il est légitime ou acceptable de faire appel à des sources diverses espacées dans le temps et l'espace, si une observation ethnographique moderne au Guatemala peut éclairer un rite décrit par un chroniqueur métis du XVI siècle dans l'altiplano central, ou si une pratique rituelle moderne permet de comprendre un reste archéologique d'époque classique. On a déjà gâché trop d'encre et de papier à ces questions. Que ceux que cela intéresse en fassent l'historiographie. Pour moi, lorsque l'on veut essayer de comprendre ou d'expliquer un aspect culturel quelconque, il est légitime de faire feu de tout bois, à condition bien sûr de s'efforcer au respect de la cohésion interne. La logique interne du modèle présenté, sa fonctionnalité, est le seul critère vraiment important. Lorsque Knorosov se mit au travail pour essayer de déchiffrer l'écriture maya, il demanda à son maître Sergei Tokarev quelle méthode il devrait adopter. Celui-ci lui répondit: la seule chose importante c'est le résultat. Si l'on s'était construit moins de barrières et de cloisons, on aurait peut-être remarqué depuis longtemps les ressemblances frappantes entre la geste de Quetzalcóatl et la pièce du Rabinal Achi. La critique systématique des sources, des intentions cachées des auteurs, des non-dits, des mal dits, des contre-sens, des mensonges et propagandes me dépasse. Pour moi, tout cela est beaucoup trop compliqué, et trop incertain. Certainement les informations originales sont souvent biaisées d'une manière ou d'une autre, mais en choisissant celles qui le seraient ou celles qui ne le seraient pas et en 
les rectifiant dans un sens ou dans un autre, on les biaise une deuxième fois, il faudrait donc passer sa vie à éplucher tous les avis contraires et en tirer certaines conclusions, elles aussi nécessairement biaisées. Tout cela biaiserait les auteurs critiques une fois, les chroniqueurs deux fois et la vérité historique trois fois, et l'on finirait pas se biaiser soi-même. On objectera donc sans doute dans le présent travail l'absence d'analyse critique des sources citées et utilisées. Le seul critère retenu a été celui de la cohérence interne. Le présent travail propose seulement une optique particulière en espérant qu'elle permette de résoudre un grand nombre d'énigmes sinon toutes, et de convaincre le lecteur, de gagner sa compréhension voire son adhésion à notre point de vue. A qui faire confiance? Durán dénonce la duplicité des indiens qui sous couvert de chrétienté continuent leurs anciennes dévotions, ici pour la fête des morts, mais il dit bien, que cette technique était générale:

Plega a nuestro señor sea verdad y que estén raídos de su memoria, pero témome que no lo están en algunos, porque, como ellos tenían sus fiestas de difuntos, una de difuntos menores y otra de mayores, creo - y sin creo- podremos afirmar que mezclarán algo de ello con nuestra fiesta de difundos, como mezclan con las demás, cantando sus funerales responsos, llorando sus señores y dioses antiguos, $y$, porque no lo entendemos, dicen que no se acuerdan de ellos. ${ }^{180}$

Toutes les cultures humaines sont le résultat d'innombrables emprunts et brassages, de réinterprétations et réadaptation des ruines du passé. Pourquoi devrionsnous êtres plus pédants avec les anciens mexicains que nous ne le sommes avec les chrétiens? La chrétienté elle-même est le fruit d'un mélange d'éléments culturels des plus variés, assemblés de manière syncrétique. Mon parti-pris est donc de garder les sources de première, deuxième ou troisième main telles qu'elles se présentent, comme matière brute et matériaux pour ma propre réflexion. La seule critique consistant à relever les contradictions entre les auteurs, les contradictions internes de chaque auteur, et essayer de comprendre la logique interne du système social et de pensée des cultures de la Mésoamérique préhispanique.

Le texte des Annales de Cuauhtitlan se présente comme une chronique de la vie de Quetzalcóatl, mais de fait, il ne nous présente presque uniquement que les conditions de sa mort. Nicholson faisait la même remarque à propos des Toltèques et de Tollan en général:

I80. Durán, Historia de las Indias de Nueva España, I: V: 50: 56. 
The «fall» of Tollan and the consequent diaspora of its people are, as would be expected, more fully covered in the sources than the antecedents of the Toltecs and their history during the flowering of their capital. This was clearly the most momentous, well-remembered incident in pre-Hispanic Central Mexican political history until the turbulent events of the late fourteenth and fifteenth centuries in the Basin of México and, not surprisingly, left a profound mark on the historical consciousness of Tollan's successor polities. ${ }^{181}$

Et puis, n'est-il pas étrange que le roi termine sa vie par un suicide rituel, sa propre immolation, qui servira de modèle au sacrifice en général, alors que la raison première avouée de sa chute, causée par la haine de ses ennemis, et orchestrée par les prêtres avait été précisément son obstination à refuser les sacrifices humains. Pour finir il choisira plutôt de s'exiler et de s'immoler soimême plutôt que de céder aux pressions cruelles de ses ennemis. Voilà un bel et noble acte de courage rédempteur, pourtant, si nous lisons attentivement le texte, nous soupçonnons que notre vaillant héro n'avait sans doute plus d'autre choix que de présenter contre mauvaise fortune bon cœur, et jouer le jeu avec dignité pour sauver au moins l'honneur, la dernière de ses cartes. Le roi nous apparait en fait comme un prisonnier étranger destiné au sacrifice. Ángel María Garibay dit du théâtre préhispanique:

Haré sencilla la exposición diciendo que en la dramática náhuatl hallamos ya en germen la división de especies: la que celebraba grandes hechos y la que solamente tiene por misión divertir al espectador. Sin remedio tenemos que llamar a la primera tragedia y a la segunda comedia, tal como las llamaron los griegos. ${ }^{182}$ Et plus loin: Más que hablar de un drama náhuatl puede decirse que hay una colección de cuadros melodramáticos. Eran para dar veneración a los dioses o los héroes y para dar esparcimiento a los magnates. Eran éstos los principales espectadores, aunque el pueblo no estaba excluido de las representaciones generales que se hacían en las

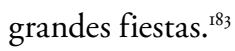

I8I. Nicholson, Topiltzin Quetzalcóatl, the Once and Future Lord, 270.

I82. Ángel Ma. Garibay K., Poesía náhuatl, 3 vols. (Ciudad de México: Universidad Nacional Autónoma de México, I993), III: X.

I83. Garibay, Poesía nábuatl, III: XII. 
Je ne serais pas d'accord avec une partie de ce jugement. S'il est vrai qu'il ne nous est parvenu que des fragments de styles et de genres différents, et que cela donne l'impression de «una colección de cuadros melodramáticos», je retiendrais plutôt les termes de dramática nahuatl; tragedia et comedia. Le terme mélodramatique est par trop méprisant et avec le mystère préhispanique nous avons à faire à une passion tragique et poignante, un questionnement existentiel dramatique, fut-il parfois exprimé ou accompagné de fragments comiques ou burlesques. Cette tragédie s'exprime il est vrai parfois par des formes surprenantes. Pour certains esprits la tragédie et le sacrifice religieux, la GrandMesse, s'accordent mal avec d'autres représentations, tels que celles du cabaret, du cirque, de la magie, de l'escamotage, de l'opéra, du guignol. Il n'est pourtant pas si difficile de comprendre ces voisinages. Seules les situations les plus cruelles produisent les formes d'humour les plus tordantes. Après les horreurs de la Grande Guerre et le génocide perpétué par les bolcheviques bienfaiteurs de l'humanité, quelques fous sublimes purent imaginer le théâtre de la cruauté comme expression suprême de l'art. ${ }^{184}$ Fleurissent alors des auteurs tels qu'Antonin Artaud, Jaroslav Hasek, Michail Boulgakov, Isaac Babel. Le rire est la forme ultime de la douleur, sa sublimation. Comme chez Rimbaud en enfer: Et le printemps m'a apporté l'affreux rire de l'idiot. Cette association du plus tragique des spectacles et du rire burlesque dans les rituels a été remarqué notamment par le Professeur Curt Sachs ${ }^{185}$ qui dans son Histoire de la danse, écrit:

En guise d'antidote et par un retour du pendule, la folie sacrée donne le jour à des danses burlesques. Aux côtés du danseur possédé de l'esprit divin, nous voyons apparaître le bouffon. Chez les Indiens d'Amérique et en passant par les mers du Sud et l'Asie jusqu'en Europe, il prend une part souvent décisive aux danses. Il caricature les exécutants, effraie les spectateurs, harcèle les jeunes filles et pénètre les mystères de la vie et de la mort: dans la danse du scalp des IndiensCheyenne, des clowns portaient le costume de l'ennemi abattu; dans les danses des couvents tibétains, l'on voit figurer aux côtés de deux bouffons, deux autres personnages vêtus de maillots blancs collants sur lesquels est peint le squelette humain et qui portent des têtes de mort. ${ }^{186}$

I84. Voir Antonin Artaud, Oeuvres complètes, t. 4, Le théâtre et son double (Paris: Gallimard, 1964).

I85. Kurt Sachs, Histoire de la danse (Paris: Gallimard, I938), 2.

I86. Michel Leiris, La possession et ses aspects théâtraux chez les Éthiopiens de Gondar (Paris: Plon, 1958). 
Alfonso Caso relève cet aspect grotesque de certaines représentations dédiées à Quetzalcóatl:

There were special dramas performed in honor of Quetzalcóatll, the god of the wind and the hero-founder of agriculture and industry. The characters in these dramas were grotesque, deformed people and impersonalisations of animals. Dialogue was highly spontaneous. In a hunting scene the sharp repartee between the hunter and the clever animals amused the spectator. ${ }^{187}$

Le problème qui a pu arrêter, me semble-t-il, nombre de chercheurs, c'est justement ce mélange inextricable de tous les genres peu coutumier de l'esprit de notre époque, un spectacle total pour tous les publics. Il n'empêche que le cœur, le noyau de toutes ces représentations confondues est une tragédie parfaitement structurée et qui touche tous les hommes, et la comparaison avec Hamlet ou CEdipe n'est pas si gratuite qu'il pourrait y paraitre. Ne trouve-ton pas aussi dans le Quetzalcóatl l'enfance marginale, l'orphelinage, la quête du père et la vengeance, l'oncle usurpateur, l'inceste, la question de l'être: un drame universel. Lorsque j'écrivais ci-dessus que «ce mélange inextricable de tous les genres peu coutumier de l'esprit de notre époque», ce n'est pas tout à fait vrai. Traditionnellement aussi en Europe, le jour de la fête du village est avant tout le jour de la fête patronale de l'église locale, une grand-messe chantée solennelle qui rappelle le sacrifice suprême du Christ comme aussi celui du saint Patron. Mais aux mêmes jours on trouvait aussi souvent la foire annuelle, les commerces ambulants, le marché aux bestiaux, les défilés en fanfare, la fête foraine, le guignol, le cirque, le bal et les grands banquets, les batifolages de la jeunesse en préludes aux futures unions.

Nous allons donc relire les sources concernant Quetzalcóatl et leurs commentaires comme fragments de descriptions de mystères religieux donnés en spectacle dans le théâtre préhispanique. ${ }^{188} \mathrm{~A}$ vrai dire les études sur le théâtre

I87. A. Caso, The Aztec People of the Sun, ed. Lowell Dunham (Norman: University of Oklahoma Press, 1958), XV.

I88. Plusieurs auteurs historiens, anthropologues lettrés, ont bien vu le caractère éminemment théâtral de la geste de Quetzalcóatl, au point même de produire des pièces dramatiques pour la scène. Alfredo Chavero (Alfredo Chavero, Quetzalcóatl ensayo trágico en tres actos y en versos [Ciudad de México: impr. de Jens y Zepiain, 1878]) et Miguel León Portilla (Miguel León Portilla, La huida de Quetzalcóatl [Madrid: Fondo de Cultura Económica de España, 200I]) ont produit chacun une pièce de theâtre sur Quetzalcóatl. 
de mystère préhispanique ne sont pas nombreuses, René Acuña le remarquait déjà à propos des mayas pourtant bien mieux documentés que les cultures de l'altiplano:

Las farsas y representaciones escénicas de los mayas antiguos constituyen un territorio todavía poco explorado... Frente al teatro ceremonial de los mayas, el europeo pudo sentir a veces deslumbramiento tal vez, pero siempre perplejidad. La lengua extrańa de los cantares, lo desusado del baile y de la armonía musical de los instrumentos, las máscaras representando seres y rostros muchas veces monstruosos, los cuerpos semidesnudos de los danzantes, a veces escondidos en parte bajo la piel de felinos y de animales salvajes, o bien bajo los bordados de ricas plumas de aves exóticas, $y$, al fin los sacrificios humanos, debieron producir cierto pasmo en el europeo, cuando no repugnancia. Además, ¿¿Cómo comprender aquellos juegos escénicos cuyo simbolismo era tan complicado y extrańo como las tubas de barro y de asta de ciervo, como el sonido perturbador de las trompas de caracol, o como el tono ronco de los tunkules? Cuando, aun ahora, el ojo entrenado y disciplinado del observador etnográfico deja escapar tanta variedad de detalles, ¿Cómo pedirle al europeo de entonces, lleno de prejuicios occidentales, que hubiera reparado en el color de las plumas de los tocados, en la forma de los collares y ajorcas, en los dibujos de las rodelas, en el tiempo y ocasión de los bailes? Cada una de estas cosas, sin embargo, era significativa e importante para entender el teatro ceremonial de los pueblos de Mesoamérica. ${ }^{189}$

A propos du théâtre de Bali, Antonin Artaud écrit que:-Le premier spectacle du théâtre Balinais qui tient de la danse, du chant, de la pantomime, de la musique, - et excessivement peu du théâtre psychologique tel que nous l'entendons ici en Europe, remet le théâtre à son plan de création autonome et pure, sous l'angle de l'hallucination et de la peur. ${ }^{190}$ Nous pouvons parfaitement adapter, et sans aucune hésitation, me semble-t-il, ces vues au théâtre mésoaméricain, et même plus encore qu'à celui de Bali. Au Mexique tout était joué en dansant, la vie des dieux, des héros, des rois:

I89. René Acuña, Farsas y representaciones escénicas de los mayas antiguos (Ciudad de México: Universidad Nacional Autónoma de México, I978), II-I2.

190. Artaud, Le theâtre et son double, 64 . 
Y esos bayles mas solenes heran hechos en las fiestas generales y tanbien particularmente de sus dioses, y hazianlas en las plaças. En estas no solo llamauan e honrrauan e alabauan a sus dioses con cantares de la boca, mas tanbien con el corazon y con los sentidos del cuerpo. Para lo qual bien hazer tenian e usuauan de muchas memorativas, ansi en los meneos de la cabeça de los braços y de los pies como con todo el cuerpo trabajauan de llamar y seruir a los dioses... Estos yndios de Anauac en sus libros y manera de escritura tenian escrito los vençimientos y victorias que de sus henemigos auian auido. Y los cantares dellos sabianlos y solezinauanlos con bailes y danças, bendiziendo y confesando a sus demonios por los quales creian auer avido vitoria contra sus enemigos. Y por estas memoria hazian en sus fiestas aquellos actos, trabajos y cantares. ${ }^{191}$

Encore un mot. J'essaierai de ne pas tomber dans deux travers trop fréquents, celui de l'idéalisme qui veut tout voir tout beau et tout justifier au seul nom de l'impartialité scientifique et de son dogme: ne jamais juger, et surtout, pour ne pas paraître faire le jeu d'un eurocentrisme dominant, excuser et justifier dans d'autres cultures ce qui ne saurait se tolérer dans la nôtre. Les problèmes abordés ici concernent souvent l'humanité dans son ensemble et posent de graves problèmes sur la nature humaine. Mon regard critique sur certaines pratiques ne cherche pas à déprécier les mésoaméricains préhispaniques mais plutôt certaines constantes tragiques des errements de la culture, et l'étude de Mésoamérique peut beaucoup nous enseigner pour la compréhension d'autres sociétés dont il ne reste plus que des restes archéologiques, je pense en particulier aux sociétés agricoles du néolithique européen, comme aussi à la nôtre qui en constitue le prolongement. Je ne ferai pas non plus aux Mexicains d'autrefois l'affront de les croire plus primitifs que nous-même. Leurs questionnements et interrogations sont humains tout simplement, leurs réponses comme celles des autres cultures sont mélangées de sublime et de bassesse, de cruauté et d'absurde et reflètent des angoisses existentielles qui sont aussi les nôtres.

Les arguments sont nombreux qui montrent que le Quetzalcóatl des textes et traditions est l'accumulation des représentations figurées de la vie et de la 
mort du dieu. Dans cette courte présentation nous n'en pouvons rappeler que quelques traits essentiels. ${ }^{192}$

fueron los toltecas a traer a Quetzalcóatll para constituirle rey en Tollan. ${ }^{193}$ Cette formulation à elle seule pourrait constituer la preuve que toute l'affaire de cette monarchie de Tollan est une construction rituelle. Les Toltèques sont allés chercher un certain Quetzalcóatl pour en faire leur roi! On ne nous indique pas non plus d'où l'on avait été le chercher. Mais on nous informe bien ici que Quetzalcóatl n'était pas originaire de Tollan et qu'on l'y amena pour l'y déclarer roi. Un étranger donc. Chimalpahin confirme que Quetzalcóatl ne naquit pas à Tollan, mais y apparut:

Año 4-Tochtli, IOO2 ańos. Aqui en este nacio Topiltzin Acxitl Quetzalcohuatl alla en Tullan. Pero no nacio en verdad, puesto que solamente llego cuando vino a manifestarse en ese lugar. ¿de donde vino? No se sabe bien, tal como lo iran diciendo los antiguos. Por entonces lleva dieceocho años de asumir el mando Totepeuh, tlatohuani de Culhuacan. ${ }^{194}$

I-Tochtli, 2-Acatl. ${ }^{195}$ Ce sont les années du Feu Nouveau dans le système calendaire du Mexique central, c'est donc à l'occasion de ces fêtes que l'on a été chercher Topiltzin, notre prince, notre fils bien aimé, un prisonnier, la victime sacrificielle. C'est effectivement ainsi que le prêtre Tezcatlipoca s'adresse à lui: «Hijo mio». ${ }^{196}$

En este año 2-Acatl edifico Topiltzin Ce Acatl Quetzalcóatll su casa de ayunos, lugar de su penitencia y oracion. ${ }^{197}$ Durán et bien d'autres auteurs signalent que la construction de cabanes rituelles et de lieux de pénitence et de prières était

192. Il est probable que l'étude complète qui compte presque 600 pages sera publiée en 202I par тав Edizioni, Roma.

193. Annales, 33.

194. Chimalpahin I99I: II; Año 4-Tochtli, IOO2. Remarquons ici l'équivalence, une autre fois de Tollan et Culhuacan.

195. Annales, 34,35.

196. Annales, 39, $4 \mathrm{I}$.

197. Annales, 35 . 
bien en effet l'une des occupations obligées des prisonniers ixiptlas des dieux: «el edificar templos y altares y el poner ídolos en ellos, el ayunar». ${ }^{198}$

estaba dentro de un aposento muy obscuro y custodiado; le custodiaban sus pajes en muchas partes, que cerraban; su aposento era el último, y en cada uno estaban sus pajes. ${ }^{199}$ Quetzalcóatl était un prisonnier. Il vit donc au fond d'un cachot, bien gardé. Duran et Joseph de Acosta nous en disent tout autant de l'ixiptla de Tezcatlipoca: «Este hombre representaba vivo a este ídolo aquellos quaranta dias. El cual era servido y reverenciado como a tal; traía su guardia y otra mucha gente que le acompañaba todos aquellos días. También lo enjaulaban de noche porque no se le uyese». ${ }^{200}$

Hagamos pulque; se lo daremos a beber, para hacerle perder el tino. ${ }^{201}$ On le fait boire pour l'étourdir. Pour le décider à bien vouloir entrer en scène et partir pour l'autre monde «que bebiendola conseguireis el fin de vuestros intentos, que será ir a los Reinos que deseais». ${ }^{202}$ La formulation est machiavélique, évidemment on lui fait dire qu'il a lui-même choisi de partir vers l'autre monde, la victime doit être consentante. Nombreux sont les textes qui mentionnent l'usage de boissons narcotiques pour la préparation de la victime. Duran rappelle la boisson que l'on servait à l'image de Cihuacoatl, nommée aussi Quilaztli et Xilonen: «Traíanla siempre embriagada, fuera de su natural juicio; unos dicen que con bino, otros, que, demas de darle vino, le daban no sé que héchicos juntamente para que andando siempre alegre, no se acordase que había de morir ${ }^{203}$ Le baron des Quiches reclame lui aussi la boisson qui efface l'amertume, «las doce bebidas... Las probaré un instante, como suprema señal de mi muerte». ${ }^{204}$

Estando ya alegre Quetzalcóatll, dijo: Id a traer a mi hermana mayor Quetzalpetlatl. ${ }^{205}$ Quetzalcóatl réclame une femme. L'expression ma sour est une

198. Durán, Historia de las Indias de Nueva España, I: I: 24, 1984: 13.

199. Annales, 38.

200. Durán, Historia de las Indias de Nueva España, I: VI: IO-II; 1984: 63; Joseph de Acosta,

$\mathrm{V}: 30 ;$ Historia natural y moral de las Indias, 276.

20I. Annales, 39.

202. Torquemada, Monarquí indiana, VI: XXIV; II: 49: I.

203. Durán, Historia de las Indias de Nueva España, II: XIII: 9, I984: I26.

204. Blixen, «Rabinal Achi», 68.

205. Annales, 42. 
courtoisie, Durán la présente autrement: «con mucho secreto le abían metido dentro a una ramera, que entonces vivía, muy desonesta, que avia nombre Xochiquetzal». ${ }^{206}$ Pour la victime du sacrifice, c'était de coutume, et la chose avait été prévue depuis l'aube de l'aventure aztèque, dès le début de la migration, par leur dieu tribal Huitzilopochtli, faisant partie du plan de conquêtes, on devait faire des prisonniers à sacrifier au dieu et les traiter au mieux avant de les immoler: «la víspera de su muerte, velarán toda la noche, comerán, danzarán y se emborracharán; y si acaso alguno quiere acostarse con mujeres, le serán ofrecidas prostitutas, habrá muchísimas mujeres perversas, prostitutas». ${ }^{207}$

He aqui la cancion que has de cantar. ${ }^{208}$ S'il ne s'agissait pas d'un rituel de préparation, on s'étonnerait bien de certaines incohérence du texte: Celui auquel on s'adresse avec révérence par les titres de Sacerdote, c'est-à-dire grand prêtre, ne connait pas encore bien la liturgie, les répons et les litanies du rituel dont il est l'acteur principal. Tout est organisé et orchestré par les prêtres, et l'on doit lui inculquer tout ce qu'il doit faire, ici on lui enseigne la chanson qu'il doit chanter, qu'il est tenu de chanter. L'expression employée ne fait aucun doute, et c'est un ordre: «De nuevo dijeron los demonios a Quetzalcóatl: "Hijo mío, canta, He aqui la cancion que has de cantar".» Y canto Ihuimecatl:

Mi casa de plumas de quetzalli,

mi casa de plumas de zaquan,

mi casa de corales,

la dejare, An-Ya. ${ }^{209}$

La formule nous rappelle le fragment dans lequel on le force à boire: "has de beber cuatro». ${ }^{210}$ et aussi chez Sahagún: «y le dixo, el dicho viejo. Por fuerça aueys de yr, a Tullan Tlapallan", ${ }^{211}$ ou bien encore: «diciendo que os ha de ver por fuerza». ${ }^{212}$ Tout le scenario est réglé d'avance, c'est une obligation, on n'y peut rien changer. Le chant est un chant d'adieu aux beautés et richesses de ce monde, le regret de partir déjà: «Mi casa de plumas de quetzalli, mi casa

206. Durán, Historia de las Indias de Nueva España, II: I: 30-3I, 1984: I4.

207. Del Castillo, Historia de la venida de los mexicanos, IOO-IOI.

208. Annales, 4I.

209. Annales, 4I.

210. Annales de Cuauhtitlan, 40.

2II. Sahagún, Códice Florentino, III: IV: IIv; Historia general, 3II.

2I2. Sahagún, Códice Florentino, III: IV: Iov-IIr; Historia general, 310. 
2) Ehecatl Quetzalcóatl, l'acteur Topiltzin, sculpture en pierre. Museo Nacional de Historia del Castillo de Chapultepec, Ciudad de México. Secretaría de Cultura-INAH-MÉx. "Reproducción autorizada por el Instituto Nacional de Antropología e Historia”.

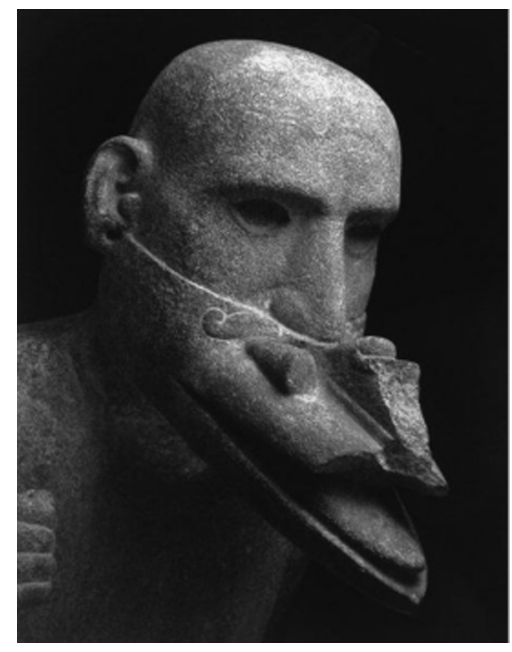

de plumas de zaquan, mi casa de corales, la dejare, An-Ya». Ceci nous rappelle une fois encore les paroles du baron des Quiché: «!Ah, oh cielo!, !Ah ho tierra!?debo, realmente, morir, fallecer aqui, bajo el cielo, sobre la tierra? ${ }_{¡} \mathrm{Oh}$ mi oro! $¡ \mathrm{Oh}$ mi plata». ${ }^{213}$

Luego hablo Tezcatlipoca: Yo digo que vayamos a darle su cuerpo. ${ }^{214}$ Il s'agit ici d'offrir au dieu, au personnage, au rôle, un corps dans lequel il pourra se glisser, se montrer, de créer un personnage au sens théâtral du terme. Il faut l'habiller, le peindre, le masquer pour pouvoir le faire sortir en public.

Hijo mio, yo digo que salgas a que te vean los vasallos; voy a alinearte para que te vean. ${ }^{25}$ Luego hizo esto Coyotlinahual, oficial de pluma. Hizo primero la insignia de pluma (apanecayotl) de Quetzalcóatll. En seguida le hizo su mascara verde; tomo color rojo, con que le puso bermejos los labios; tomo amarillo, para hacerle la portada; y le hizo los colmillos; a continuacion le hizo su barba de plumas, de xiuhtototl y de tlauhquechol, que apreto hacia atras. ${ }^{216}$

213. Blixen, «Rabinal Achi», 78.

214. Annales, 39.

215. Annales, 39.

216. Annales, 40. 
Il s'agit bien d'un costume de scène comme cela se remarque sur tant de représentations peintes ou sculptées de Quetzalcóatll, un jeune homme masqué et peint, costumé. Pour sauter dans le brasiers, à nouveau est-il là aussi bien costumé. Se atavio y se quemo. ${ }^{217}$ Le texte des Annales présente un Quetzalcóatl fortement idéalisé, un héros magnifique qui comme Nanahuatl se jette hardiment dans le brasier, et de plus il s'était d'abord fait beau, costumé, mais nous savons que les sacrifiés étaient souvent ligotés pour être sacrifiés, et il en était de même pour ceux que l'on jetait vivants au feu. D'ailleurs Mendieta donne une autre version des faits: "Mas al fin el Tezcatlipuca, como mas poderoso, le echó también de allí, y fueron con él algunos sus devotos hasta cerca de la mar, donde dicen Tlillapa ó Tizapan, y que allí murió y le quemaron el cuerpo". ${ }^{218}$

Muñoz Camargo dit aussi que les autres dieux (entendre ceux qui les représentent) le jetèrent dans la fournaise:

Dice la fábula que el sol fue un dios muy desechado, porque fue leproso o muy buboso, de modo que no se podía rodear ni parecer ante gentes. Visto por los demás dioses tan gran lástima, mandaron fabricar un horno de cal, y haciendo una muy gran foguera en el, le echaron dentro y estando ansi ardiendo que se quemara y consumiera o se purificara mas que los dioses, obieron con el tanta piedad y virtud que le convertieron en luz y le llamaron sol. ${ }^{219}$

Voilà donc bien la grande compassion et générosité des dieux (entendre les prêtres déguisés qui les représentent). Ils soignent le malheureux lépreux bubonneux en le purifiant au feu, le libèrent gratuitement d'une existence insupportable. Si le texte des Annales déclare que Quetzalcóatll se jeta luimême dans le brasier, c'est ici encore que la victime du sacrifice comme la femme violée est toujours consentante, doit l'être afin que ce ne soit pas un crime. La comparaison entre ces deux personnages n'est pas nouvelle puisqu'on la trouve clairement exprimée chez les informantes de Sahagun.

très ivre, fort abrutie, abattue, perverse; une victime sacrificielle, une esclave baignée; riche et hautaine, elle est lascive, se maquille, elle ruine les gens, se mire,

217. Annales, 50.

218. Mendieta, Historia eclesiástica indiana, II: V, 188.

219. Muñoz Camargo, Historia de Tlaxcala, I5I. 
se lave, se baigne [...] elle vit comme un esclave baigné, elle se comporte comme une victime sacrificielle. ${ }^{220}$

Certains objecterons peut être que l'on ne devrait pas confondre les prostituées et les femmes violées, mais le texte de Muñoz Camargo nous montre pourtant à propos de Xochiquetzal, la patronne des prostituées comment l'abus de l'une conduit au consentement excessif de l'autre:

A esta diosa Xochiquetzal celebraban fiesta cada año con mucha solemnidad, y a ella concurrian muchas gentes donde tenia su templo dedicado. Dicen que fue mujer del dios Tlaloc, dios de las aguas, e que se la hurto Tezcatlipoca, e que la llevo a los nueve cielos e la convirtio en diosa del bien querer. ${ }^{221}$

La victime est publique, lui un homme public, elle une femme publique, tous deux baignés excessivement, tous deux attifés et fardés excessivement, tous deux déambulant dans les rues sous bonne surveillance, arrogants et vénaux, ivres et drogués, se laissant toucher par tous, arborant une superbe et une apparente gaité, elles aussi excessives et douteuses, les deux sont très consentants, tout aussi consentants que les volontaires tchèques sur le front serbe pendant la Grande Guerre, qui, lorsqu'ils allaient à l'infirmerie pour se déclarer malades, étaient tous invariablement traités de simulateurs. Il y en eut même un, si l'on en croit Jaroslav Haszek, qui mourut de simulation à l'hôpital. Quelle grandeur, quelle merveille, l'acteur parfait. ${ }^{222}$ L'actrice parfaite.

Dans cette courte présentation de mon hypothèse, je ne puis développer tous les arguments qui démontrent que Quetzalcóatl fut un acteur, une suite d'acteurs du rôle et que toute la tradition se rapportant à Topiltzin Quetzalcóatl nous rapporte en fait divers aspects de la préparation et de la représentation théâtrale du mystère divin, ce qui nous est révélé de la manière la plus convaincante et on ne peut plus claire par un fragment du Codex de Madrid. Après avoir costumé, maquillé, masqué et bien enivré Quetzalcóatl, on va le faire

220. Graulich, Le sacrifice humain chez les Aztèques, 214-215, citant Sahagún, texte nahuatl du Códice Florentino X: XV: 38v-40r.

22I. Muñoz Camargo, Historia de Tlaxcala, i55.

222. Jaroslav Hašek, le brave petit soldat Svejk, chapitre VII. 
sortir sur scène, le montrer. Mais on doit encore finir de le décider, lui donner courage, on le fait alors chanter à l'unisson, on fait attendre la foule massée au dehors: «Entonces con sus guardianes se puso a cantar un canto. A la multitud que esperaba fuera, se la hizo esperar más». ${ }^{223}$ Pourquoi y aurait-il eu à l'extérieur une multitude? Une foule? Si ce n'est que cet évènement avait été bien organisé, préparé et annoncé depuis longtemps déjà pour que vienne de tous les alentours et souvent de très loin, à des jours de marche, le public des fidèles pour admirer la mort héroïque du dieu, du sauveur, du dieu fait homme. Il est grand temps de le faire entrer en scène, la foule attend la sortie du roi: «Notificaron a Coyotlinahual, oficial de pluma, que tenía que ir y dijo: Sea en hora buena. Voy a ver a Quetzalcóatll. Y fue y dijo a Quetzalcóatll: Hijo mío, yo digo que salgas». ${ }^{224}$ is

223. Sahagún, Códice matritense del Real Palacio, fols.132v-I34v., versión de A.M. Garibay, in León-Portilla, Cantos y crónicas del México antiguo, 76-77.

224. Annales, 39.

N. B. Ce texte constitue une partie des recherches conduites dans le cadre du projet NCN, (centre de la recherche scientifique de Pologne Nr. ID: 20I3/II/B/HSI/O4I46) sous le titre: Topiltzin jako aktor: analiza misterium religijnego prehiszpańskiej Mezoameryki oraz jego związów z aspektami kalendarzowymi i astronomicznymi. 